\title{
Polyether Adducts of d-Block Metal Compounds as Starting Materials for New Cluster Compounds
}

\author{
Aurélien Crochet ${ }^{[\mathrm{a}]}$ and Katharina M. Fromm*[a]
}

Keywords: Cobalt; Nickel; Zinc; Mercury; Polyethers; Solid state structures

Abstract. New crystalline cobalt, nickel, zinc, and mercury halide adducts with polyethers as ligands have been isolated, characterized, and identified as $\left.\left[\mathrm{Co}(\mu-\mathrm{Cl})_{2} \mathrm{CoCl}_{2} \text { (glyme }\right)_{2}\right]$ (glyme $=1,2$-dimethoxyethane), cis- $\left[\mathrm{CoI}_{2}\left(\mathrm{H}_{2} \mathrm{O}\right)_{2}(\text { glyme })_{2}\right]^{2+}\left[\mathrm{CoI}_{4}\right]^{2-}, \quad\left[\mathrm{NiI}_{2}(\text { glyme })_{2}\right], \quad\left[\mathrm{ZnI}_{2}\right.$ (glyme) $]$, $\left[\mathrm{HgCl}_{2}\right.$ (glyme) $],\left[\mathrm{CoI}_{2}\right.$ (diglyme) (diglyme $=$ bis(2-methoxyethyl)ether),
$\left[\mathrm{ZnI}_{2}(\right.$ diglyme $\left.)\right], \quad\left[\mathrm{HgI}_{2}(\right.$ diglyme $\left.)\right], \quad[\mathrm{CoCl}(\mu-\mathrm{Cl})(\text { diglyme })]_{2}, \quad[\mathrm{NiI}(\mu-$ I)(diglyme $)]_{2}, \quad[\mathrm{Co}(\mu-\mathrm{Cl})$ (triglyme $\left.)\right]_{2}{ }^{2+}\left[\mathrm{CoCl}_{2}(\mu-\mathrm{Cl})\right]_{2}{ }^{2-}, \quad$ and cis$\left[\left(\mathrm{NiI}_{2}\right) \text { (triglyme) }\right]_{n}$. These compounds were obtained from the metal halide salts in solution of glyme or diglyme, and some of them show unusual coordination numbers and arrangements.

\section{Introduction}

We are interested in molecular compounds, especially oxygen donor adducts of metal halides, because they are useful as starting materials in the synthesis of low-dimensional polymeric compounds, i.e. clusters, and polymers or metal organic frameworks [1-16]. Indeed, since more than two decades, metal aggregates are used in the low-cost synthesis of superconductors and other oxide materials based on the sol-gel technique or as volatile precursors in the MOCVD (Metal Organic Chemical Vapor Deposition) process $[3,11,13,17-21]$. One of the major problems of the synthesis of organo-metal(II) compounds, including the alkaline earth metal ions, is their possible tendency to form insoluble polymers [21-24], on one hand due to their low metal oxidation state $M^{\mathrm{II}}$, which only allows two anionic ligands, and on the other hand, their ionic radii, which demand a high coordination number. A parry to prevent a high degree of oligomerization is the use of neutral Lewis-coordinating ligands such as monodentate THF or multidentate polyether ligands, which avoid any further "metal-metal contacts" via bridging ligands, saturating the metal cation. However, the chemistry of such metal halide or pseudo-halide adducts with neutral Lewis-coordinating ligands (usually non-polar aprotic solvents) is still not systematically studied.

Compounds that have so far been isolated in the class of molecular species are, for instance, the zero-dimensional compounds trans- $\left[\mathrm{MI}_{2}(\mathrm{THF})_{n}\right](M=\mathrm{Ca}$ [25], Sr [26], Ba [2]; THF = tetrahydrofuran) or trans-[ $\left.\operatorname{SrI}_{2}(\text { glyme })_{3}\right]$ [27] (glyme $=$ ethylene

\footnotetext{
* Prof. Dr. K. M. Fromm

Fax: +41-26-300-9738

E-Mail: Katharina.fromm@unifr.ch

[a] Department of Chemistry

University of Fribourg

Chemin du musée, 9

1700 Fribourg, Switzerland
}

glycol dimethyl ether, 1,2-dimethoxyethane) and trans$\left[\mathrm{CaI}_{2}\right.$ (diglyme)(glyme)] [10]. In these molecular compounds, the metal cation is always surrounded in linear or quasi-linear fashion by the two anions, whereas the THF, glyme or diglyme ligands are found in the equatorial positions of the square bipyramid in trans- $\left[\mathrm{CaI}_{2}\right.$ (diglyme)(glyme)] or hexagonal bipyramid in trans-[ $\left.\operatorname{SrI}_{2}(\text { glyme })_{3}\right]$. Only one cis-compound, cis-[ $\mathrm{SrI}_{2}-$ $(\text { diglyme })_{2}$ ] has been described by us previously [12]. For transition metal halides with oxidation states II or III, the trans or ciscompounds, as well as higher halides or ethereal adducts are known, such as cis-[TiBr 2 (glyme $\left.)_{2}\right]\left[\mathrm{TiBr}_{4}\left(\right.\right.$ glyme $\left._{2}\right]$ [28], $\left[\mathrm{TiCl}_{4}\right.$ (glyme)] [29], [ReCl 4 (glyme)] [30], trans- $\left[\mathrm{WO}_{2} \mathrm{Cl}_{2-}\right.$ (glyme)] [31], cis-[ $\mathrm{VI}_{2}$ (glyme) $)_{2}$ [32], [ $\mathrm{MoCl}_{4}$ (glyme)] [33], $\left[\mathrm{YCl}_{3} \text { (glyme) }\right)_{2}$ [34], [VCl $($ glyme)(THF)] [35], and cis$\left.\left[\mathrm{FeCl}_{2} \text { (glyme) }\right)_{2}\right] \mathrm{FeCl}_{4}[36]$.

Alkaline earth and transition metal adducts with the tridentate diglyme ligand are much rarer than with THF or glyme: e.g. the $\left[\mathrm{ScCl}_{3}\right.$ (diglyme) $\quad[37], \quad\left[\mathrm{TiCl}_{3}\right.$ (diglyme) $\quad[38], \quad\left[\mathrm{Y}_{2}(\mu-\mathrm{OH})-\right.$ $\left(\mathrm{H}_{2} \mathrm{O}\right)_{2}(\mathrm{EtOH})_{4}$ (diglyme) $\mathrm{I}_{4}[39],[\mathrm{Mg}(\mu-\mathrm{Cl}) \mathrm{Cl}(\text { diglyme })]_{2}$ [40], and, as pseudo-halide, the complex $\left[\mathrm{ZnPh}_{2}\right.$ (diglyme)] [41]. In our own group, some complexes of alkaline earth metal ions with diglyme, such as $\left[\mathrm{SrI}_{2}(\right.$ diglyme $\left.)\right] \quad[42], \quad\left[\mathrm{Ca}\left(\mathrm{H}_{2} \mathrm{O}\right)_{2^{-}}\right.$ (diglyme $\left.)_{2}\right] \mathrm{I}_{2}$, and $\left.\left[\mathrm{Ba}\left(\mathrm{H}_{2} \mathrm{O}\right)_{3} \text { (diglyme }\right)_{2}\right] \mathrm{I}_{2}$ [8] were described.

In some cases, halide ions are replaced in the first coordination sphere of the metal atom by neutral water or polyether oxygen donor ligands for instance, leading to compounds such as $\left[\mathrm{CaI}(\text { glyme })_{3}\right] \mathrm{I}[12]$, or $\left.\left[\mathrm{Ba}\left(\mathrm{OH}_{2}\right) \text { (triglyme }\right)_{2}\right] \mathrm{I}_{2}$ [triglyme $=$ $\left.\mathrm{CH}_{3}\left(\mathrm{OC}_{2} \mathrm{H}_{4}\right)_{3} \mathrm{OCH}_{3}\right]$ [8]. In the latter case, the anions are linked to the cationic complex by hydrogen bonding to the water molecule, and remain thus in a second coordination sphere.

In this context, we have synthesized and characterized some new molecular compounds using polydentate neutral Lewiscoordinating ligands such as glyme $\left(\mathrm{CH}_{3} \mathrm{OC}_{2} \mathrm{H}_{4} \mathrm{OCH}_{3}\right)$, diglyme $\left[\mathrm{CH}_{3}\left(\mathrm{OC}_{2} \mathrm{H}_{4}\right)_{2} \mathrm{OCH}_{3}\right]$ and triglyme $\left[\mathrm{CH}_{3}\left(\mathrm{OC}_{2} \mathrm{H}_{4}\right)_{3}\right.$ $\left.\mathrm{OCH}_{3}\right]$ in order to, in a fundamental way, know and understand 
better the chemistry of d-block metal halides in aprotic solvents. Secondly, we were interested in the study of the influence of the size of the ligand on the coordination sphere of the metal cation using monodentate (THF), bidentate (glyme), tridentate (diglyme) and finally tetradentate (triglyme) O-donor ligands $[2,10]$. Finally, we wanted to compare the reactivity of the polydentate polyether-containing molecular compounds with the THF adduct ones.

\section{Results and Discussion}

\section{Compound $\left[\mathrm{CoCl}_{2} \mathrm{Co}(\mu-\mathrm{Cl})_{2}(\mathrm{glyme})_{2}\right]$ (1)}

The dissolution and recrystallization of $\mathrm{CoCl}_{2}$ in freshly dried and distilled glyme $\left(\mathrm{CH}_{3} \mathrm{OCH}_{2} \mathrm{OCH}_{3}\right)$ yields compound $\mathbf{1}$, which crystallizes in the monoclinic space group $C 2 / c$. The asymmetric unit consists of half a molecule, the latter of which is formed by a dinuclear cobalt complex. One of the cobalt atoms, Co1, is tetrahedrally coordinated by four chloride ions, two of them act as $\mu_{2}$-bridging ligands to $\mathrm{Co} 2$. This second metal ion has an octahedral coordination sphere, with two bidentate glyme-ligands in addition to the anions (Figure 1 and Figure 2). A C2 axis passes through the two cobalt cations $\mathrm{Co} 1$ and $\mathrm{Co} 2$, which are both found on the special positions [Co1: 0; y; 0.25; (e) and Co2: 0; y; 0.25 (e)]

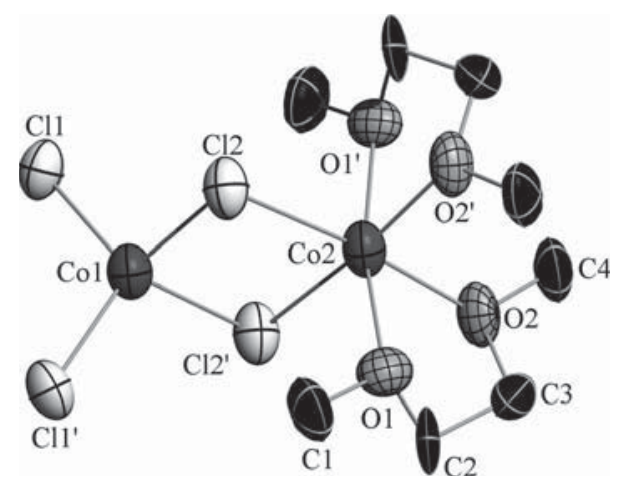

Figure 1. View of the molecular structure of $\mathbf{1}$, hydrogen atoms are omitted for clarity, $50 \%$ probability ( $=-x, y, 1 / 2-z$ ).

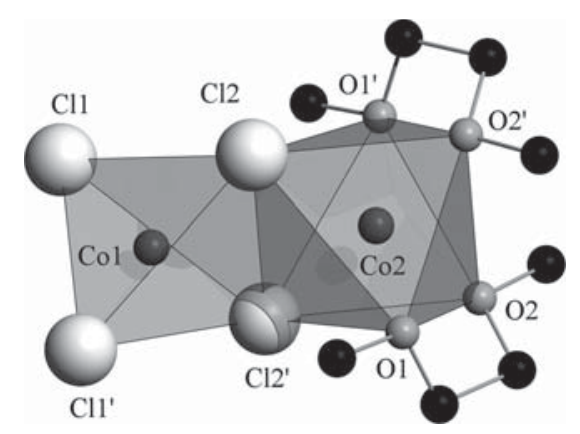

Figure 2. View of the molecular structure of $\mathbf{1}$ with polyhedral arrangement, hydrogen atoms are omitted for clarity.

For the tetrahedral cobalt ion, Col, the angle between the two chloride ligands and the cobalt ion, Cl1-Co1-Cl2-angle is with $108.9(2)^{\circ}$ close to the ideal tetrahedral angle. For Co2, the angle between the bridging chloride and the cobalt is clearly smaller with $87.6(2)^{\circ}$, whereas the angles Cl2-Co2-O1 and $\mathrm{Cl} 2-\mathrm{Co} 2-\mathrm{O} 2$ are $97.9(4)^{\circ}$ and $174.1(4)^{\circ}$, respectively. The bite angle between the two oxygen atoms of glyme O1-Co2$\mathrm{O} 2$ is $76.5(5)^{\circ}$, whereas the angle between the glyme ligands $\mathrm{O} 2-\mathrm{Co} 2-\mathrm{O} 2{ }^{\prime}$ is $92.0(6)^{\circ}$, showing the distortion of the octahedral coordination sphere. The distance Co1-Cl1 is with 2.223(6) $\AA$ as expected shorter for a terminal ligand than Co1$\mathrm{Cl} 2$ [2.326(6) $\AA$ ] for the bridging chloride. For the octahedral cobalt ion, the distance Co2-Cl2 is 2.448(6) $\AA$ and thus clearly longer than for Co1. This is expected due to the higher coordination number. The Co2-O distances are 2.103(13) $\AA$ and 2.081(14) $\AA$, indicating a slightly asymmetric coordination of glyme. The bond valence sums give values of 2.1 for the tetrahedral Co1, and 2.01 for the octahedral cobalt Co2, showing a good coordination of the metal ions [48].

The molecules are packed into layers along the $b$ axis. Within the same layer, the cobalt ions are ca. $6.6 \AA$ apart (Co1-Co2'). Between the layers, the cobalt ions are ca. $6.5 \AA$ apart (Co2-Co2").

In the literature, some examples of compounds are known, where the coordination arrangement of two distinct metal ions are different within a molecule, usually combining hexacoordinate and tetracoordinate metal ions [49, 50]. Some examples with two metal ions of the same element having different coordination modes are known, mainly with $\mathrm{N}$-donor ligands, as e.g. in $\left[\mathrm{Cd}_{2} \mathrm{Br}_{2}(\mu-\mathrm{Br})_{2}\left(\mathrm{Cl}_{15} \mathrm{H}_{12} \mathrm{~N}_{4}\right)_{2}\right],\left[\mathrm{Cd}_{2} \mathrm{I}_{2}(\mu-\mathrm{I})_{2}\left(\mathrm{C}_{15} \mathrm{H}_{12} \mathrm{~N}_{4}\right)_{2}\right]$ [51], $\quad\left[\mathrm{Cd}_{2} \mathrm{Br}_{2}(\mu-\mathrm{Br})_{2}\left(\mathrm{Cl}_{15} \mathrm{H}_{12} \mathrm{~N}_{4}\right)_{2}\right] \quad[52], \quad\left[\mathrm{Hg}_{2} \mathrm{Cl}_{2}(\mu-\mathrm{Cl})_{2^{-}}\right.$ $\left(\mathrm{C}_{15} \mathrm{H}_{12} \mathrm{~N}_{4}\right)_{2}$ ] [53], $\left[\mathrm{Hg}_{2} \mathrm{Cl}_{2}(\mu-\mathrm{Cl})_{2}\left(\mathrm{C}_{16} \mathrm{H}_{36} \mathrm{~N}_{4}\right)\right.$ ] [54], or [Fe $(\mu-$ $\mathrm{I}_{2} \mathrm{I}_{2}$ (isoprop $)_{4}$ ] [55]. Only one example of such different coordination modes for cobalt is described to the best of our knowledge, namely $\left[\mathrm{Co}_{2} \mathrm{Cl}_{2}(\mu-\mathrm{Cl})_{2}(1,10-\text { phen })_{2}\right]$ [56]. Thus, com-

Table 1. Comparison of glyme compound 1 and $\left[\mathrm{Co}_{2} \mathrm{Cl}_{2}(\mu-\mathrm{Cl})_{2}(1,10-\right.$ phen) 2 .

\begin{tabular}{|c|c|c|}
\hline Compound & 1 & {$\left[\mathrm{Co}_{2} \mathrm{Cl}_{2}(\mu-\mathrm{Cl})_{2}(1,10 \text {-phen })_{2}\right]$} \\
\hline Formula & $\mathrm{C}_{8} \mathrm{H}_{20} \mathrm{Cl}_{4} \mathrm{Co}_{2} \mathrm{O}_{8}$ & $\mathrm{C}_{24} \mathrm{H}_{16} \mathrm{Cl}_{4} \mathrm{Co}_{2} \mathrm{~N}_{4}, \mathrm{C}_{4} \mathrm{H}_{10} \mathrm{O}$ \\
\hline Mol. Wt. & 645.73 & 694.22 \\
\hline Crystal system & Monoclinic & Monoclinic \\
\hline Space group & $C 2 / c$ & $C 2 / c$ \\
\hline$a / \AA$ & $13.687(4)$ & $10.278(2)$ \\
\hline$b / \AA$ & $9.9885(14)$ & $22.026(5)$ \\
\hline$c / \AA$ & $12.883(3)$ & $12.941(3)$ \\
\hline$\beta /{ }^{\circ}$ & $101.124(19)$ & $103.959(4)$ \\
\hline$V / \AA^{3}$ & $1728.2(7)$ & 2843.11 \\
\hline$Z$ & 4 & 4 \\
\hline $\mathrm{Cl1}-\mathrm{Co} 1 / \AA$ & $2.223(6)$ & $2.2248(5)$ \\
\hline $\mathrm{Cl} 2-\mathrm{Co} 1 / \AA ̊$ & $2.326(6)$ & $2.3321(6)$ \\
\hline $\mathrm{Cl1}-\mathrm{Co} 1-\mathrm{Cl1}{ }^{\prime} /{ }^{\circ}$ & $114.5(3)$ & $109.74(1)$ \\
\hline $\mathrm{Cl} 2-\mathrm{Co} 1-\mathrm{Cl} 2^{\prime} /{ }^{\circ}$ & $93.5(2)$ & $96.43(1)$ \\
\hline $\mathrm{C} 12-\mathrm{Co} 2 / \AA ̊$ & $2.448(6)$ & $2.4748(6)$ \\
\hline $\mathrm{Co} 2-\mathrm{C} 11 / \AA$ & $2.103(13)$ & $2.1260(6)$ \\
\hline $\mathrm{Co} 2-\mathrm{Cl} 2 / \AA$ & $2.081(14)$ & $2.1224(6)$ \\
\hline $\mathrm{Cl} 2-\mathrm{Co} 2-\mathrm{Cl} 2^{\prime} /{ }^{\circ}$ & $87.6(2)$ & $89.28(1)$ \\
\hline tetrahedral volume $/ \AA^{3}$ & 5.893 & 5.961 \\
\hline octahedral volume $/ \AA^{3}$ & 14.103 & 14.741 \\
\hline BVS. Co1 & 2.1 & 2.08 \\
\hline BVS. Co2 & 2.01 & 1.72 \\
\hline
\end{tabular}


pound $\mathbf{1}$ is a new example of this kind of coordination, and the first example with O-donor stabilization. The two cobalt compounds, the one from the literature and ours, are compared in Table 1. Whereas the tetrahedral part of the molecules resemble each other very well, the octahedrally coordinated cobalt cation in the literature compound is less well coordinated by the 1,10-phen ligand than with glyme in $\mathbf{1}$, as the bond valence sums show.

\section{Compound cis- $\left[\mathrm{CoI}_{2}\left(\mathrm{H}_{2} \mathrm{O}\right)_{2}(\text { glyme })_{2}\right]^{2+}\left[\mathrm{CoI}_{4}\right]^{2-}$ (2)}

The dissolution of $\mathrm{CoI}_{2}$ in freshly dried and distilled glyme followed by slow evaporation gives green crystals. Compound 2 crystallizes in the monoclinic space group $P 2_{1} / c$ with two molecules A and B per asymmetric unit (Figure 3). Molecule $\mathrm{A}$ is composed of one cobalt ion surrounded by four iodide anions with Co-I of 2.60(2), 2.623(2), 2.598(2), and 2.590(2) $\AA$ for I1, I2, I3 and I4, respectively, and angles of 109.17(6) for I1-Co1-I2, 107.38(6) for I1-Co1-I3, and $109.83(6)^{\circ}$ for $\mathrm{I} 1-\mathrm{Co} 1-\mathrm{I} 4$. The so formed tetrahedron is slightly distorted, e.g. by the short contact of iodide ions with hydrogen atoms of molecule B. B is composed of one cobalt atom coordinated by six oxygen atoms, four of them are oxygen atoms from two glyme molecules, the two others are water molecules. The Co-O distances to oxygen atoms of glyme vary between 2.086(8) and 2.116(8) $\AA$ for O2, and O4, respectively, whereas the distance $\mathrm{Co}-\mathrm{O}$ to the water molecules is $2.070(8) \AA(\mathrm{O} 5)$ and 2.067(8) $\AA(\mathrm{O} 6)$. The bite angles of the glyme molecules are with $78.0(3)^{\circ}$ for $\mathrm{O} 1-\mathrm{Co} 2-\mathrm{O} 2$, and $78.7(3)^{\circ}$ for $\mathrm{O} 3-\mathrm{Co} 2-\mathrm{O} 4$ almost identical. The angle between the two oxygen atoms of water is $92.8(3)^{\circ}$, which indicates a cis coordination of the latter. The angles O1-Co2-O3, O1Co2-O4, O1-Co2-O5, and O1-Co2-O6 are 171.0(3), 94.5(3), 98.1(3), and $93.0(3)^{\circ}$, respectively. The bond valence sums method gives values of 2.06 for the tetrahedral Co1, and 2.04 for the octahedral cobalt $\mathrm{Co} 2$, showing a good coordination of the metal ions [48].

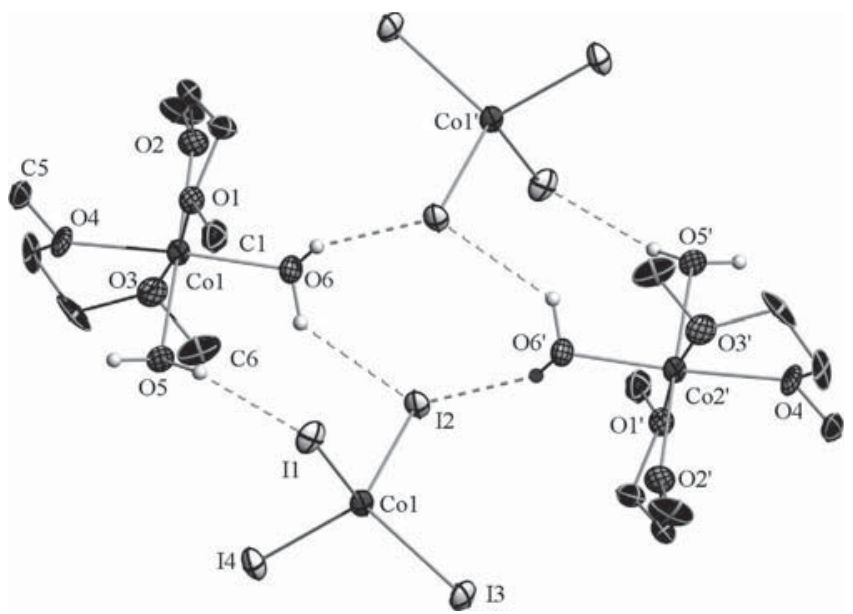

Figure 3. Views of the molecular structure of $\mathbf{2}$ with hydrogen bonds indicated as dashed lines, some hydrogen atoms are omitted for clarity, $50 \%$ probability (' $=-x, 2-y, z-1)$.

The tetrahedral volume of $\mathrm{A}$ is $9.020 \AA^{3}$ and the octahedral volume of B is $12.004 \AA^{3}$. These two molecules A and B form short contacts via hydrogen atoms of water, which are oriented in direction of I1 and I2 and the methyl group of $\mathrm{C} 1$ has short contact with I4 (Figure 3). The presence of water in compound 2 was introduced accidentally during the crystallization process. Under the same conditions, a water-free nickel iodide adduct with glyme could be obtained.

\section{Compound [cis-NiI (glyme $_{2}$ ] (3)}

The dissolution and recrystallization of $\mathrm{NiI}_{2}$ in freshly dried and distilled glyme yields a clear brown solution, which turns orange during the crystallization process of $\mathbf{3}$. Compound $\mathbf{3}$ crystallizes in the monoclinic space group $P 2_{1} / c$ with two independent molecules A and B per asymmetric unit, each consisting of a nickel cation $\mathrm{Ni1}$ and $\mathrm{Ni2}$, two iodide anions and two glyme ligands are bonded, the latter in a bidentate fashion. The coordination arrangement can be described as distorted octahedral with two iodide ions in cis positions and four oxygen atoms (Figure 4). In molecule A, the I1-Ni1-O4 and I2Ni1-O1 angles are far from linear with values of $169.52(11)^{\circ}$ and $171.95(14)^{\circ}$, respectively. This is partially due to the bite angle of the glyme ligands, which vary from $79.2(2)^{\circ}$ to $79.4(2)^{\circ}$. The angle between the two iodide ions I1 and I2 is with $96.94(3)^{\circ}$ larger than the expected $90^{\circ}$ for a perfect octahedron. For molecule $\mathrm{A}$, the $\mathrm{Ni}-\mathrm{O}$ bonds for the first glyme ligand are 2.089(5) (O1) and 2.139(5) $\AA$ (O2), showing a slightly asymmetric binding of the ligand. For Ni1-O3 and Ni1-O4 of the second glyme molecule, the distances are with 2.105(4) and 2.102(5) $\AA$ much more symmetric. The Ni-I bonds are 2.68(9) and 2.70(8) $\AA$ long, thus slightly asymmetric. For the second molecule B, the distances Ni2-O5, Ni2O6, Ni2-O7, and Ni2-O8 are 2.136(5), 2.086(6), 2.127(6) and 2.083(5) $\AA$, respectively, showing that both glyme ligands are coordinating in an asymmetric fashion. The Ni2-I distances are with 2.6787(9) and 2.6719(9) $\AA$ similar than in molecule A. The angles between the two iodide ions with $97.06(3)^{\circ}$, and the glyme bite angles of $79.5(2)$ and $79.9(2)^{\circ}$ are similar to the ones in molecule $\mathrm{A}$.
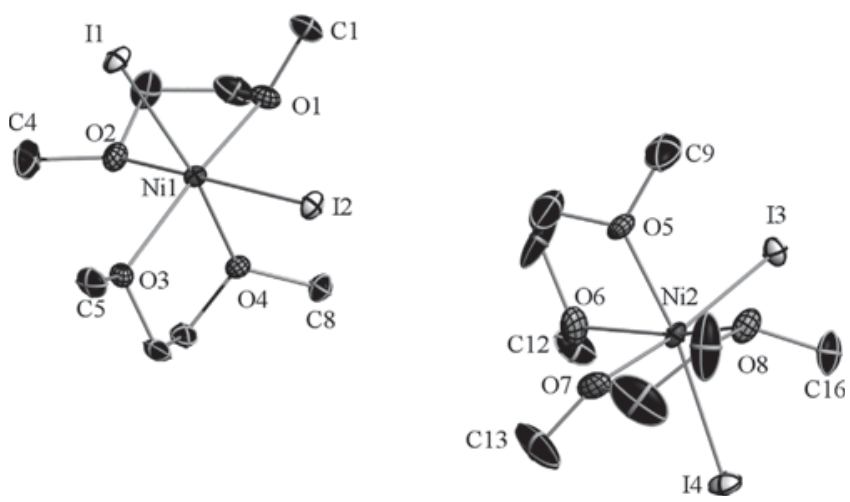

Figure 4. View of the molecular structure of $\mathbf{3}$, hydrogen atoms are omitted for clarity, $20 \%$ probability.

The two molecules are crystallographically independent, but each molecule has short contacts between iodide and a hydrogen atom of the $\mathrm{CH}_{2}$-group of the next molecule. For the mole- 
cule A, I1 has a short contact of $3.03 \AA$ with one hydrogen atom of $\mathrm{C} 2$, whereas for molecule $\mathrm{B}$, I4 has short contacts with hydrogen atoms of $\mathrm{C} 14$ and $\mathrm{C} 15$ (3.16 and $1.18 \AA$ ). The bond valence sum for Ni1 amounts 2.08 $\AA$, and $2.12 \AA$ for Ni2 [48].

Another synthesis of compound 3 (but not its structure) has been described previously [57] using crystalline nickel iodide pentahydrate, which was dried with triethylorthoformate and recrystallized from anhydrous, peroxide free, hot 1,2-dimethoxyethane, forming a blood red solution, followed by slow evaporation at 250 mbar. The syntheses of dichloro(glyme)nickel and dibromo(glyme)nickel are also described and elementary analyses indicated that the nickel ion is in this case tetracoordinate, contrary to compound 3 . Dibromo(glyme)nickel finds it application in the catalysis of $[2+2+2+2]$ cycloadditions of terminal diynes for the synthesis of substituted cyclooctatetraenes [58]. Compound 3 does not show catalytic activity.

\section{Compound [ZnI 2 (glyme)] (4)}

The synthesis of compound $\mathbf{4},\left[\mathrm{ZnI}_{2}\right.$ (glyme)], was not described previously, but a homologue, $\left[\mathrm{ZnBr}_{2}\right.$ (glyme)], was

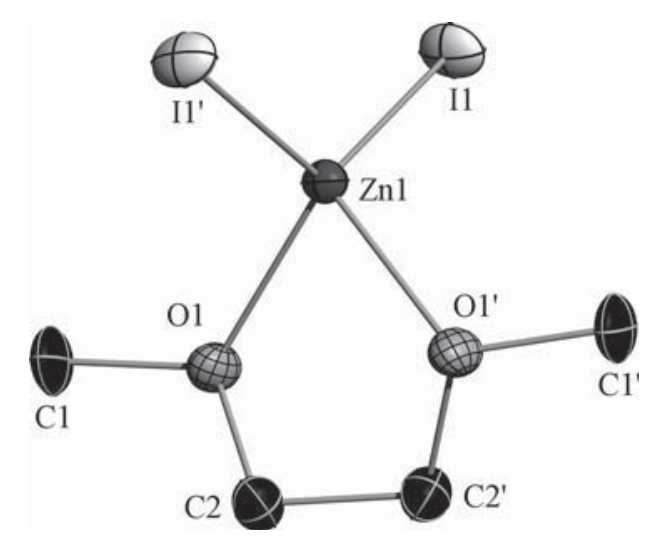

Figure 5. View of the molecular structure of 4 , hydrogen atoms are omitted for clarity, $50 \%$ probability (' $=-x, y, 1 / 2-z$ ). published previously [59], however with only elemental analysis as characterization method.

The dissolution and recrystallization of $\mathrm{ZnI}_{2}$ in freshly dried and distilled glyme yields compound 4 , which crystallizes in the orthorhombic space group Pbcn (60). The molecular unit consists of one zinc cation, to which two iodide anions and one glyme ligand are bonded. The coordination arrangement can be described as distorted tetrahedral, with a $\mathrm{C} 2$ axis passing through $\mathrm{Zn} 1[0, y, 0.25(c)]$ as well as the geometrical middle between $\mathrm{C} 2$ and C2' (Figure 5). The angle between the two anions is $126.55(6)^{\circ}$ and the bite angle of glyme between the two oxygen atoms is $79.3(3)^{\circ}$, showing deviation from ideal tetrahedral arrangement. The distance $\mathrm{Zn} 1-\mathrm{I} 1$ is 2.503(1) $\AA$, whereas the $\mathrm{Zn}-\mathrm{O}$ bond is, as expected for the smaller though neutral oxygen atom, much shorter with 2.067(7) $\AA$.

The molecules are arranged into layers, stacking along the $c$ axis. Within the same layer, the zinc ions are ca. $6.3 \AA$ apart, whereas between two neighbor layers, a short contact of $3.7 \AA$ between the iodine $\mathrm{I} 1$ of one molecule and $\mathrm{C} 1$ of glyme of a neighbor molecule is found, possibly indicating I $\cdots H$ contacts. The bond valence sum method gives a value of 2.11 for the zinc cations, showing satisfactory coordination of the cation [48].

In analogy, Markies et al. published a structure of tetracoordinate diphenylzinc with one glyme as ligand [41]. This compound is, together with the bromide homologue and to the best of our knowledge, the only one example of tetracoordinate zinc with one glyme as ligand. In Table 2, the diphenylzinc compound is compared with compound $\mathbf{4}$ for the most important structural features. It turns out that the diphenylzinc compound crystallizes also in an orthorhombic space group, but with twice as many molecules per asymmetric unit than $\mathbf{3}$. Also, the bite angle of glyme is by ca. $7^{\circ}$ smaller in the literature compound than in $\mathbf{4}$, indicating the flexibility of the glyme binding capacity.

\section{Compound [ $\mathrm{HgCl}_{2}$ (glyme)] (5)}

In apparent analogy, the mercury analogue is obtained by dissolution and recrystallization of $\mathrm{HgCl}_{2}$ in freshly dried and

Table 2. Comparison of $\mathrm{Zn}$-glyme adducts $\mathbf{4 ,} \mathbf{5}$ and $\left[\mathrm{ZnPh}_{2}\right.$ (glyme)].

\begin{tabular}{llll}
\hline Compound & $\mathbf{4}$ & {$\left[\mathrm{ZnPh}_{2}(\right.$ glyme $\left.)\right]$} & $\mathbf{5}$ \\
\hline Formula & $\mathrm{C}_{4} \mathrm{H}_{10} \mathrm{O}_{2} \mathrm{I}_{2} \mathrm{Zn}$ & $\mathrm{C}_{16} \mathrm{H}_{20} \mathrm{O}_{2} \mathrm{Zn}$ & $\mathrm{C}_{4} \mathrm{H}_{10} \mathrm{O}_{2} \mathrm{Cl}_{2} \mathrm{Hg}$ \\
Mol. Wt. & 409.32 & 309.71 & 361.61 \\
Crystal system & Orthorhombic & Orthorhombic & $\mathrm{Monoclinic}$ \\
Space group & $P b c n$ & $P b c a$ & $12 / c$ \\
$a / \AA$ & $13.3660(6)$ & $12.554(1)$ & $14.879(17)$ \\
$b / \AA$ & $7.2700(7)$ & $14.062(1)$ & $7.2358(6)$ \\
$c / \AA$ & $10.744(1)$ & $18.288(1)$ & $8.2891(10)$ \\
$\beta /{ }^{\circ}$ & 90 & 90 & $99.268(10)$ \\
$V / \AA^{3}$ & $1044.00(2)$ & $3228.5(8)$ & 880.78 \\
$Z$ & 4 & 8 & 4 \\
$X_{x}-M 1 / \AA$ & $2.503(1)$ & $1.9695(5), 1.958(5)$ & $2.310(5)$ \\
$X_{x}-M 1-X_{y} /{ }^{\circ}$ & $126.55(6)$ & $146.7(2)$ & $166.7(2)$ \\
$M 1-\mathrm{O}_{x} / \AA$ & $2.067(7)$ & $2.287(4), 2.259(4)$ & $2.61(1)$ \\
$\mathrm{O}_{x}-M 1-\mathrm{O}_{y} /{ }^{\circ}$ & $79.3(3)$ & $72.16(14)$ & $65.1(2)$ \\
tetrahedral volume $/ \AA^{3}$ & 5.336 & 4.029 & 5.168 \\
\hline
\end{tabular}


distilled glyme to yield compound $\mathbf{5}$, which crystallizes in the monoclinic space group $C 2 / c(15)$. The molecular unit consists of one mercury cation, to which two iodide anions and one glyme ligand are bonded. In contrast to $\mathbf{4}$, the coordination arrangement can be described as extremely distorted tetrahedral, with a $\mathrm{C} 2$ axis passing through $\mathrm{Hg} 1$ as well as the geometrical middle between $\mathrm{C} 2$ and $\mathrm{C} 22^{\prime}$ (Figure 6). The angle between the two anions is $166.7(3)^{\circ}$ showing extreme deviation from ideal tetrahedral arrangement and the bite angle of glyme between the two oxygen atoms is $65.1(7)^{\circ}$.

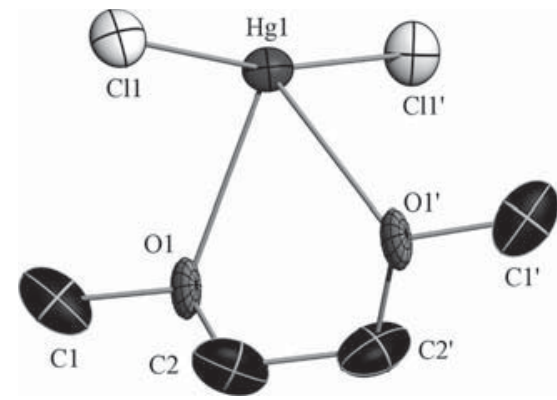

Figure 6. View of the molecular structure of $\mathbf{5}$, hydrogen atoms are omitted for clarity, $70 \%$ probability (' $=-x+1, y,-z+3 / 2$ ).

The bond valence sum method gives a value of 2.01 for the mercury cations, showing a good coordination of the cation [48].

The molecules are arranged into twisted ladders with interactions between chlorine and mercury atoms of neighbor molecules at a distance $\mathrm{Hg}-\mathrm{Clb}$ of 3.275(6) $\AA$, and angles $\mathrm{Cl}-\mathrm{Hg}-$ $\mathrm{ClIb}$ of $79.2(2)^{\circ}$, and $\mathrm{Clb}-\mathrm{Hg}-\mathrm{Clc}$ of $142.9(2)^{\circ}$. The twist of the ladder arrangement is due to this latter angle (see Table 2).

In order to investigate possible structural changes upon coordination of a tridentate ligand compared to glyme, we analyzed the structures of the transition metal(II) halides with diglyme.

\section{Compounds $\left[\mathrm{MI}_{2}(\right.$ diglyme $\left.)\right][\mathrm{M}=\mathrm{Co}(6), \mathrm{Zn}(7)$, and $\mathrm{Hg}(8)]$}

The dissolution of $\mathrm{MI}_{2}$ in dried diglyme $\left(\mathrm{CH}_{3} \mathrm{OCH}_{2} \mathrm{OCH}_{2} \mathrm{OCH}_{3}\right)$ yields in the case of $M=\mathrm{Co}$ to compound 6, which crystallizes in the orthorhombic space group $P n a 2_{1}$. The asymmetric unit consists of one cobalt cation Co1 to which two iodide ions I1 and I2 as well as one diglyme ligand are coordinated (Figure 7), resulting in the rather unusual coordination number of five for cobalt. The coordination arrangement can be described as a strongly distorted trigonal bipyramid with $\mathrm{O} 1$ and $\mathrm{O} 3$ in roughly axial positions. The I1Co1-I2 angle and the angles between the iodides and the central oxygen $\mathrm{O} 2$ correspond more or less to the triangular basis of the bipyramid. The angles with the two other oxygen atoms together with the O1-Co1-O3 angle shows the strong distortion of the polyhedron (Figure 7), which might also be described as distorted square pyramid. The bond valence sum gives a value of 1.91 , indicating a rather insufficient coordination of the metal ion in $\mathbf{6}$ [48].

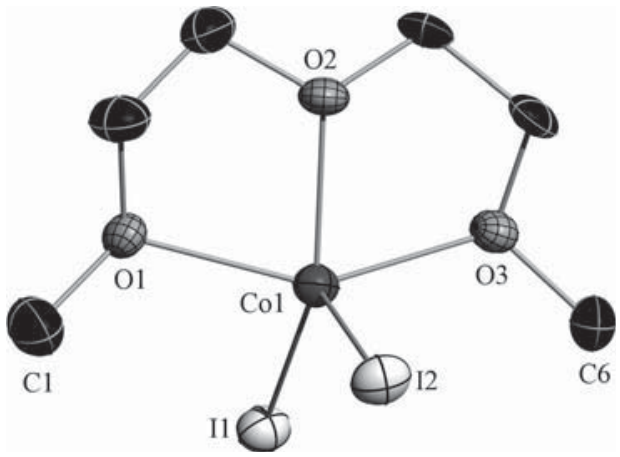

Figure 7. View of the molecular structure of $\mathbf{6}$, hydrogen atoms are omitted for clarity, ellipsoids with $50 \%$ probability.

The preferential coordination numbers of cobalt are four and six, but some examples of pentacoordinate cobalt halides with $\mathrm{N}$-donors are found in the literature. In the CSD (version 5.30, update September 2009), 105 pentacoordinate cobalt compounds with $\mathrm{N}$ - or $\mathrm{O}$-donors and two halides are found, among which only one has two iodides as anions, $\left[\mathrm{CoI}_{2}\left(\mathrm{C}_{23} \mathrm{H}_{22} \mathrm{FN}_{3}\right) \mathrm{CH}_{2} \mathrm{Cl}_{2}\right]$ [60], thus compound $\mathbf{6}$ is the first example of a pentacoordinated cobalt compound, in which three oxygen atoms and two iodides act as donor-atoms.

The compound derived from $\mathrm{ZnI}_{2}$ (7) crystallizes in the orthorhombic space group $P n a 2_{1}$. The asymmetric unit consists of one zinc cation bonded by two iodide anions and one diglyme ligand, isotypical to 6 (Figure 8).

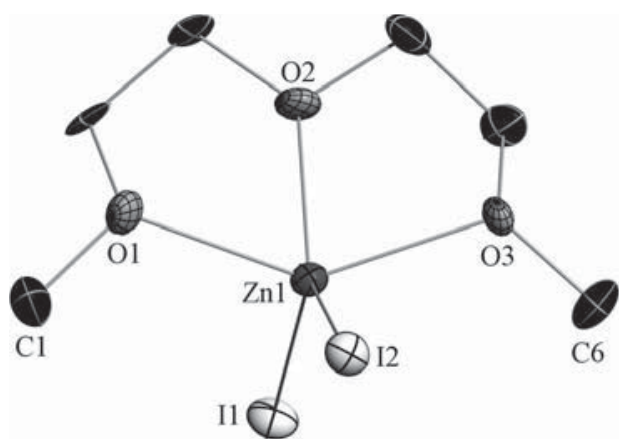

Figure 8. View of the molecular structure of 7, hydrogen atoms are omitted for clarity, $50 \%$ probability.

The angle between the two iodide anions is $124.97(5)^{\circ}$ and between the neighbor oxygen atoms $74.2(3)^{\circ}(\mathrm{O} 1-\mathrm{Zn} 1-\mathrm{O} 2)$ and $73.5(3)^{\circ}(\mathrm{O} 2-\mathrm{Zn} 1-\mathrm{O} 3)$. The distorted angle values between the iodide anions and the oxygen are atoms; one might better describe the coordination arrangement as square pyramidal, with one iodide, I1, in apical position (O1-O2-O3 $107.21^{\circ}, \mathrm{O} 2-\mathrm{O} 3-\mathrm{I} 288.16^{\circ}, \mathrm{O} 3-\mathrm{I} 2-\mathrm{O} 173.59^{\circ}$, and $\mathrm{I} 2-\mathrm{O} 1-\mathrm{O} 2$ $\left.88.13^{\circ}\right)$. The distance between the zinc ions and the basal mean plane of the three oxygen atoms and I 2 is ca. $0.75 \AA$ (Figure 8) Such flexible coordination arrangements are easily possible for a $d^{10}$-ion, which in principle does not have any preferential ligand field.

The molecules are arranged in chains along the $a$ axis, and within the same chain, all the molecules have the same orienta- 
tion. The neighbor chains within a plane still have the same orientation, whereas in the planes above and below, their orientation is opposite, thus compensating the dipole moments. Within a same plane, the zinc ions of one unit are at ca. $5.18 \AA$ to $\mathrm{O} 2$ of the diglyme molecule of the next molecule. The distance between two planes measured from one zinc ion to the next is ca. $4.34 \AA$. The bond valence sum method gives a value of 2.03, showing good coordination of the metal ion [48]. The pentacoordinate mode of the zinc ions is known, but neutral examples with two coordinated iodide ions are rare: only two compounds can be found in the CSD (version 5.30 November 2008), both with N-donor atoms $[61,62]$. The only other pentacoordinate zinc ion with three oxygen atoms of diglyme, the only other compound is $\left[\mathrm{Zn}(\mathrm{Ph})_{2}\right.$ (diglyme) $)$ published by Markies [41].

Even though compound $\mathbf{8}$ has a similar chemical composition, its case is different from the previous two. Compound $\mathbf{8}$ crystallizes in the triclinic space group $P \overline{1}$. The asymmetric unit consists of one mercury cation bonded by two iodide anions and one diglyme ligand, similar as in $\mathbf{6}$ and 7. The coordination arrangement can be described as an extremely distorted trigonal bipyramid with two iodides and one oxygen atom $\mathrm{O} 2$ in equatorial positions, and $\mathrm{O} 1$ and $\mathrm{O} 3$ in the axial positions (Figure 9).

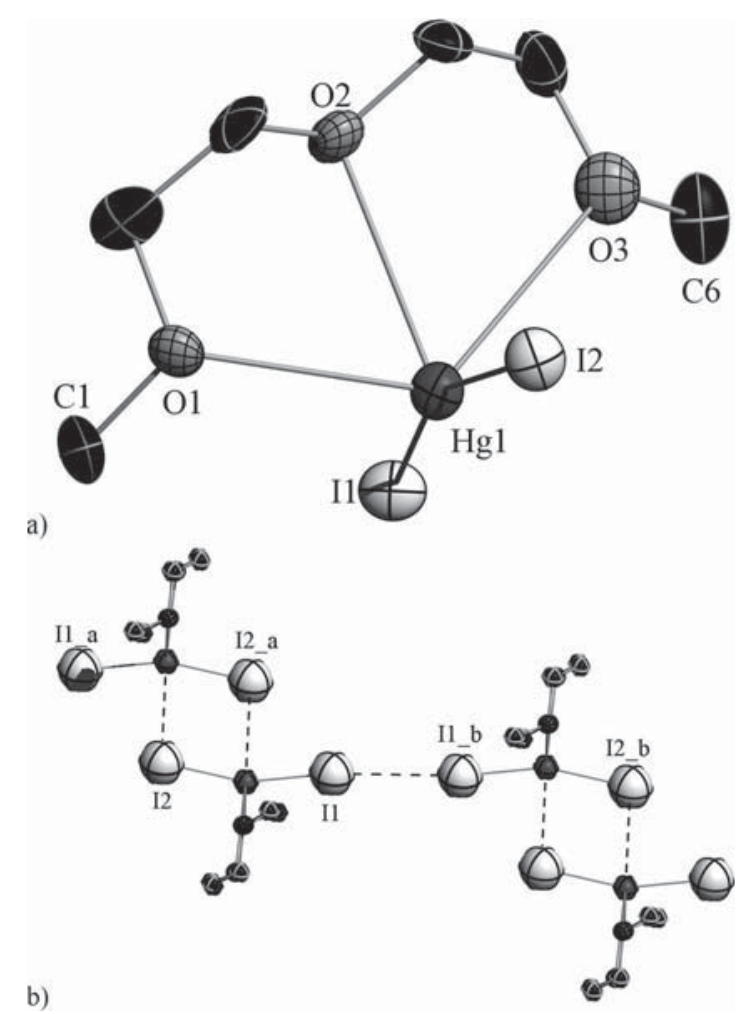

Figure 9. a) View of the molecular structure of 8 (50\% ellipsoids), hydrogen atoms are omitted for clarity. (b) View of $\mathbf{8}$ with short contacts (in dashed lines); $\mathrm{a}=-x,-1-y, 1-z ; \mathrm{b}=-x,-1-y, 2-z$.

The angle between the two iodide anions is $160.94(5)^{\circ}$, hinting that the halide ions rather adopt axial positions. The angles between the neighbor oxygen atoms are $62.0(4)^{\circ}(\mathrm{O} 1-\mathrm{Hg} 1-$
$\mathrm{O} 2)$ and $61.9(4)^{\circ}(\mathrm{O} 2-\mathrm{Hg} 1-\mathrm{O} 3)$. These values are smaller than for the previously described compounds, due to the presence of a larger cation. Some short contact between I 2 of one molecule and $\mathrm{Hg} 1$ of a neighbor molecule of 3.988(2) $\AA$ is found, admitted the ionic radii of $\mathrm{Hg}^{2+}$ being $1.02 \AA$ for a hexacoordinate mercury ion, and $0.96 \AA$ for a tetracoordinate one. Then the mercury ion can be considered as octahedrally coordinated. In addition, the I1-ions of two neighbor molecules are $3.842(2) \AA$ apart from each other, and given the ionic radii of $\mathrm{I}^{-}$with $2.2 \AA$, these two iodide ions seem to be in contact. Such short I $\cdots$. I contacts have been discussed previously for bismuth iodide complexes, and range between 3.9 and $4.0 \AA$, inferring interesting SHG properties to the literature compound [63]. Examples with short I $\cdots$ I contacts in $\mathrm{HgI}_{2}$ compounds can be found, e.g. 45 compounds with an I...I contact in the range of 3.7-4.2 $\AA$, but only five are below $3.9 \AA$, one of them with a S-donor [64], two with $\mathrm{N}$-donors $[65,66]$, one with a Pdonor [67] and one with a polyether, the dibenzo-18-crown-6 [68]. The distance in this compound is $3.880 \AA$. Compound 6

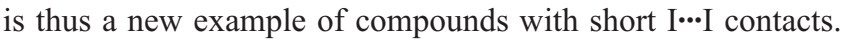

In the literature, examples of mercury(II) halides coordinated with polyethers can be found, particularly with crown ether ligands, such as in $\left[\mathrm{HgI}_{2} \mathrm{C}_{12} \mathrm{H}_{24} \mathrm{O}_{6}\right]$ [69], and $\left[\left(\mathrm{HgCl}_{2}\right)_{2}\left(\mathrm{C}_{24} \mathrm{H}_{32} \mathrm{O}_{8}\right)\right]$ [70]. In the latter crown ether compound, two mercury atoms are pentacoordinate, and two oxygen atoms of the crown ether ligand are not used for the coordination. In 1993, Rogers published the structure of diiodotetraethyleneglycol-mercury(II) [68], and in this compound, the mercury is also pentacoordinate, with two iodide and three oxygen atoms. These examples are the only ones of pentacoordinate mercury halide with three oxygen atoms, and compound 6 is a third example.

Table 3 compares compounds $\mathbf{6}$ to $\mathbf{8}$ with the literature zinc compound discussed earlier. Whereas in compounds $\mathbf{6}$ and 7 , the halide ions clearly prefer the equatorial positions in the distorted trigonal pyramid with $\mathrm{I}-M-\mathrm{I}$ angles close to $120^{\circ}$, as expected from VSEPR theory, the basal carbon atoms in the literature compound form an angle of ca. $150^{\circ}$ with the zinc ion, tending more into the axial positions.

Compounds $[M X(\mu-X)(\text { diglyme })]_{2}[M=C o, X=C l(9) ; M=$ $\mathrm{Ni}, \mathrm{X}=\mathrm{I}(10)]$

As already hinted at in compound $\mathbf{8}$, another way of forming octahedral compounds from pentacoordinate units is the dimerization. For compounds $\mathbf{9}$ and $\mathbf{1 0}$, this effect is much more pronounced than in $\mathbf{8}$.

The $\mathrm{CoCl}_{2}$ derivative with diglyme (9) crystallizes in the monoclinic space group $P 2_{1} / c$. In 9, two cobalt cations are linked to each other by two $\mu$-bridging chloride anions $\mathrm{Cl} 1$ and Cl1' (Figure 10). In the geometrical middle of the so formed rhombus, an inversion center is found. The octahedral coordination of each cation is completed by one terminal chloride ion and one diglyme molecule. The molecular unit can thus be described as two edge-sharing octahedra. Each cobalt cation is thus surrounded by three oxygen atoms of diglyme and three 
Table 3. Comparison of diglyme compounds 6, 7, 8 and $\left[\mathrm{Zn}(\mathrm{Ph})_{2}(\right.$ diglyme $\left.)\right]$.

\begin{tabular}{|c|c|c|c|c|}
\hline Compound & 6 & 7 & {$\left[\mathrm{Zn}(\mathrm{Ph})_{2}(\right.$ diglyme $\left.)\right]$} & 8 \\
\hline Formula & $\mathrm{C}_{6} \mathrm{H}_{14} \mathrm{I}_{2} \mathrm{O}_{3} \mathrm{Co}$ & $\mathrm{C}_{6} \mathrm{H}_{14} \mathrm{I}_{2} \mathrm{O}_{3} \mathrm{Zn}$ & $\mathrm{C}_{18} \mathrm{H}_{24} \mathrm{O}_{3} \mathrm{Zn}$ & $\mathrm{C}_{6} \mathrm{H}_{14} \mathrm{I}_{2} \mathrm{O}_{3} \mathrm{Hg}$ \\
\hline Mol. Wt. & 446.918 & 453.39 & 353.78 & \\
\hline Crystal system & Orthorhombic & Orthorhombic & Orthorhombic & Triclinic \\
\hline Space group & $P_{n a 2}$ & Pna $_{1}$ & $P c a b$ & $P \overline{1}$ \\
\hline$a / \AA$ & $14.3582(3)$ & $14.4305(2)$ & $12.284(1)$ & $7.5607(4)$ \\
\hline$b / \AA$ & $9.9766(3)$ & $10.0024(4)$ & $16.278(2)$ & $8.2738(5)$ \\
\hline$c / \AA$ & $8.7439(3)$ & $8.7120(3)$ & $18.595(2)$ & $12.0869(7)$ \\
\hline$\alpha /{ }^{\circ}$ & 90 & 90 & 90 & $108.041(4)$ \\
\hline$\beta /{ }^{\circ}$ & 90 & 90 & 90 & $89.917(4)$ \\
\hline$\gamma / 0$ & 90 & 90 & 90 & $112.091(4)$ \\
\hline$V / \AA^{3}$ & $1252.53(1)$ & $1257.5(1)$ & $3718.2(7)$ & $660.45(7)$ \\
\hline$Z$ & 4 & 4 & 8 & 2 \\
\hline$X_{x}-M / \AA$ & $2.5897(15), 2.6010(15)$ & $2.5556(16), 2.5502(16)$ & $1.970(8), 1.969(8)$ & $2.5975(13), 2.5953(14)$ \\
\hline$\hat{M}-\mathrm{O} 2 / \AA$ & $2.050(6)$ & $2.114(7)$ & $2.330(5)$ & $2.729(13)$ \\
\hline$M-\mathrm{O}_{y} / \AA$ & $2.163(6), 2.156(6)$ & $2.208(7), 2.213(7)$ & $2.483(5,2.509(6)$ & $2.694(12), 2.826(14)$ \\
\hline$X 1-M-X 2 /{ }^{\circ}$ & $120.86(5)$ & $124.97(5)$ & $149.7(3)$ & $160.94(5)$ \\
\hline$X_{x}-M-\mathrm{O} 2 /{ }^{\circ}$ & $136.8(2), 102.4(2)$ & $101.7(2), 133.3(2)$ & $106.1(3), 104.2(3)$ & $101.9(3), 96.3(3)$ \\
\hline$X_{x}-M-\mathrm{O}_{y} /{ }^{\circ}$ & $\begin{array}{l}93.97(17), 93.92(18), \\
101.62(17), 100.90(19)\end{array}$ & $\begin{array}{l}102.0(2), 102.90(19), 94.0(2), \\
94.34(19)\end{array}$ & $\begin{array}{l}94.4(3), 95.2(3), 95.2(3), \\
96.6(3)\end{array}$ & $\begin{array}{l}95.5(3), 92.4(3), 97.9(3), \\
91.4(3)\end{array}$ \\
\hline Polyhedral volume $/ \AA^{3}$ & 10.116 & 10.153 & 8.402 & 6.515 \\
\hline BVS & 1.91 & 2.028 & & \\
\hline Flack parameter & 0.20 & 0.32 & & \\
\hline
\end{tabular}

chloride ions; two of them act as bridging ligands to the next cation.

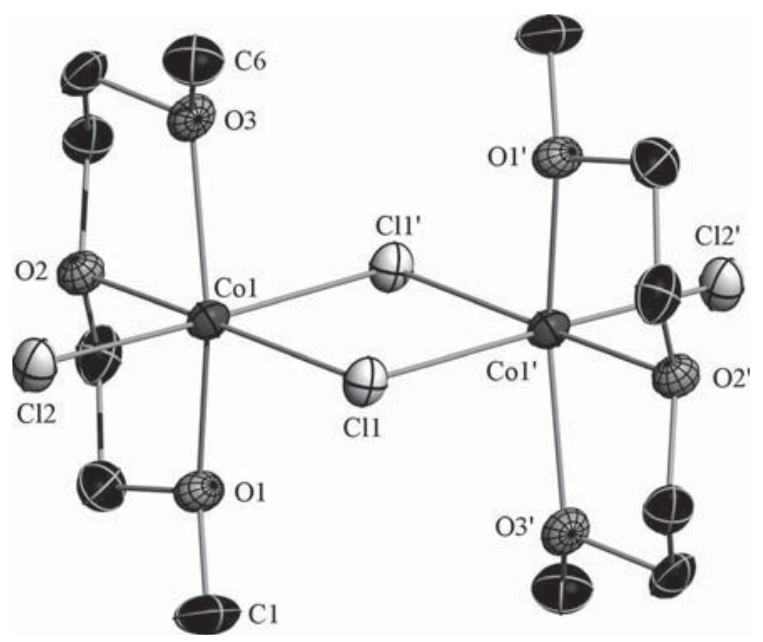

Figure 10. View of the molecular structure of 9, hydrogen atoms are omitted for clarity, $50 \%$ probability ( ' $=1-x, 1-y, 1-z)$.

The diglyme ligand adopts a meridional coordination mode with $\mathrm{O} 1-\mathrm{Co} 1-\mathrm{O} 2$ and $\mathrm{O} 2-\mathrm{Co} 1-\mathrm{O} 3$ bite angles of $77.82(11)^{\circ}$ and $76.47(11)^{\circ}$, respectively, and an O1-Co1-O3 angle of $151.86(11)^{\circ}$ for the oxygen atoms trans to each other. In the same molecule the cobalt ions are separated by $3.6 \AA$. Magnetic measurements on compound 9, carried out in collaboration with the Wieghardt group, leads to a coupling between the two metal ions with $J 12=-0.264$ and $g 1=g 2=2.620$, leading to a $\mu_{\text {eff }}=5.15 \mu_{\mathrm{B}}$. In the literature compound $\left[\mathrm{Co}_{4} \mathrm{Cl}_{8}(\text { thf })_{6}\right]$, we find a similar value for a similar bridging systems and metal-metal distance of $3.6 \AA$ [71].
The bond valence sum gives a value of 1.97 , indicating a slight under-coordination of the metal cation [48].

The $\mathrm{NiI}_{2}$-analogon $\mathbf{1 0}$ crystallizes in the monoclinic space group $P 2_{1} / c$, the inversion center is found in the middle of the molecule as in 9. Indeed, similar to $\mathbf{9}$, it forms a dinuclear complex, in which two nickel ions are $\mu$-bridged by two iodide anions, each carrying furthermore a terminal iodide ion and a diglyme ligand (Figure 11). Again, the diglyme ligand adopts a meridional coordination mode with slightly larger $\mathrm{O}_{x}-\mathrm{Ni1}-$ $\mathrm{O}_{y}$ angles than for 9 of $78.64(17)^{\circ}$ and $78.75(18)^{\circ}$, respectively, and an O1-Ni1-O3 angle of $155.86(17)^{\circ}$ for the oxygen atoms trans to each other. The angle between the two $\mu-\mathrm{I}$ is $86.13(3)^{\circ}$, between I2 and I1 $93.26(13)^{\circ}$, and between I1 and O2 $177.31(14)^{\circ}$. The angles with the two other oxygen atoms, I1-Ni1-O1 and I1-Ni1-O3, are 99.82(12) ${ }^{\circ}$ and $102.43(12)^{\circ}$, respectively. The Ni-I distances are $2.6647(8)$ for $\mathrm{Il}$ and 2.7191(9) $\AA$ for $\mathrm{I} 2$, and thus accordingly longer than $\mathrm{Co}-\mathrm{Cl}$ bonds. The Ni-O bonds are with 2.110(5) for O1, 2.058(4) for O2, and 2.104(5) $\AA$ for $\mathrm{O} 3$ similar to the Co-O bonds in 9. In the same molecule the nickel ions are distant by $4 \AA$, naturally larger than the metal-metal distance in 9 due to the larger anions. Salehzadeh presented three compounds with a $\mathrm{Ni}-\mu-\mathrm{Cl}$ bridge between two nickel metal ions, and with a $\mathrm{Ni}-\mathrm{Ni}$ distance of ca. 3.6 $\AA$. In these cases, the $\chi \mathrm{T}$ values are in good agreement with the one expected for two uncoupled $\mathrm{Ni}^{\mathrm{II}}$ spins [72-75].

The bond valence sum gives a value of 2.14, confirming good coordination by the ligands [48].

Very recently, the structure of $[\mathrm{NiBr}(\mu-\mathrm{Br})(\text { diglyme })]_{2}$ was registered in the CCDC database by Rheingold (code: COTJEB). This compound also crystallized in the monoclinic space group $P 2_{1} / c$, the $\mathrm{Ni}-\mathrm{O}$ and $\mathrm{Ni}-\mathrm{Ni}$ distances are very similar to the ones in $\mathbf{1 0 .}$ 


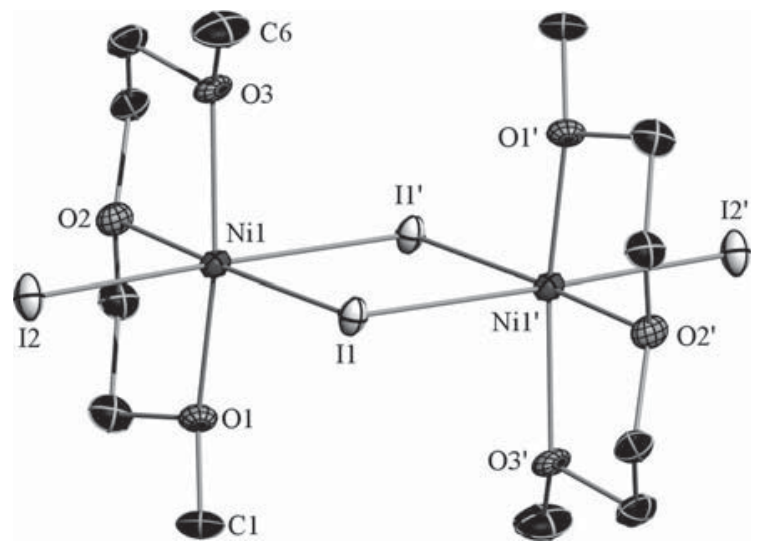

Figure 11. View of the molecular structure of 10, hydrogen atoms are omitted for clarity, $50 \%$ probability ( ' $=1-x, 1-y,-z$ ).

Another homologue within the series of dimeric, halidebridged diglyme adducts is a $\mathrm{MgBr}_{2}$ derivative [40]. Each cation carries a terminal halide ion and a diglyme ligand. In Table 4, compounds $\mathbf{9}$ and $\mathbf{1 0}$ are compared for their most important structural features with the magnesium compound.

From Table 4, it can be derived that the $M-X$ bonds to terminal halide ligands vary as expected, with the shortest bond for the chloride compound $\mathbf{9}$, and the longest one for compound 10 with iodide. The $M-X$ bonds to the bridging ions show however one surprise. Whereas the ones for the chloride compound 9 are the shortest, one expects the $M-X$ distances in the magnesium compound to be longer, but shorter than in $\mathbf{1 0}$. This is the case, but for one distance, which is with 2.822(8) $\AA$ far longer than the shortest $M-\left(\mu-X^{\prime}\right)$ in compound $\mathbf{1 0}$ with $2.6647(8) \AA$. This could be due to packing effects, and, indeed, the $\mu-\mathrm{Br}$ atom has two short contacts, one with $\mathrm{CH}_{3}$ from diglyme of a next molecule with a $\mathrm{Br}-\mathrm{C}$ distance of 3.51(2) $\AA$ and the second short contact of 2.969(3) A with one hydrogen atom from $\mathrm{CH}_{2}$ of a second molecule. The angles for these two contacts are $\mathrm{Br} \cdot \mathrm{CH}_{3}-\mathrm{O} 169(1)^{\circ}$ for the methyl group and 151(1) ${ }^{\circ}$ for $\mathrm{Br} \cdots \cdot \mathrm{H}-\mathrm{C}$ for the $\mathrm{CH}_{2}$. We can observe the same configuration of short contacts with 9 but without major impact on $\mathrm{Co}-(\mu-\mathrm{Cl})$ distances, $\mathbf{1 0}$ has also short contacts with $\mathrm{CH}_{3}$ from next molecules but the same short contacts are observed for the two $\mu$-I of the molecule.

Triglyme is an even larger ligand, for which much less examples are found in the literature. Indeed, crystallization of triglyme adducts became more difficult, and only two examples are reported below, whereas the other transition metal halides used previously did not lead to identifiable products so far.

\section{Compound $\left.[\mathrm{Co}(\mu-\mathrm{Cl})(\text { triglyme })]_{2} / \mathrm{Co}(\mathrm{Cl})(\mu-\mathrm{Cl})\right]_{2}(11)$}

The dissolution of $\mathrm{CoCl}_{2}$ in dried triglyme yields compound 11, which crystallizes in the monoclinic space group $P 2_{1} / c$ with two ionic species A and B (Figure 12). Species A consists of a cationic unit, in which two cobalt cations, Col and Co1' (' $=-\boldsymbol{x},-\boldsymbol{y}, \mathbf{1}-\boldsymbol{z})$ are linked to each other by two $\mu$-bridging chloride anions, $\mathrm{Cl1}$ and $\mathrm{Cl1}$ '. In the geometrical middle of the so formed rhombus, an inversion center is found. The octahedral coordination of each cation of $\mathrm{A}$ is completed by one triglyme molecule, leading to an overall charge of +2 . The cation can thus be described as two edge-sharing octahedral, each cobalt cation is surrounded by four oxygen atoms of triglyme and two chloride ions. The $\mathrm{Co}-\mathrm{Cl}$ distances are 2.3607(8) $\AA$ for $\mathrm{Cl} 1$ and 2.4039(9) $\AA$ for $\mathrm{Clla}$, the $\mathrm{Co}-\mathrm{O}$ bonds range from 2.104(2) for $\mathrm{O} 2$ to 2.157(2) $\AA$ for O4. The triglyme ligand adopts O1-Co1-O2, O2-Co1-O3, and O3-Co1-O4 angles of $77.44(9)^{\circ}, 77.58(9)^{\circ}$ and $77.60(9)^{\circ}$, respectively, and an $\mathrm{O} 1-$ Co1-O4 angle of $90.05(9)^{\circ}$. The angle between the two $\mu-\mathrm{Cl}$ atoms is $88.19(3)^{\circ}$. In cation $\mathrm{A}$, the cobalt ions are separated

Table 4. Comparison of diglyme compounds $\mathbf{9}, \mathbf{1 0}$, and $[\mathrm{MgBr}(\mu-\mathrm{Br})(\text { diglyme })]_{2}$.

\begin{tabular}{|c|c|c|c|}
\hline Compound & 9 & 10 & {$[\mathrm{MgBr}(\mu-\mathrm{Br})(\text { diglyme })]_{2}$} \\
\hline Formula & $\mathrm{C}_{12} \mathrm{H}_{28} \mathrm{Cl}_{4} \mathrm{Co}_{2} \mathrm{O}_{6}$ & $\mathrm{C}_{12} \mathrm{H}_{28} \mathrm{I}_{4} \mathrm{O}_{6} \mathrm{Ni}_{2}$ & $\mathrm{C}_{12} \mathrm{H}_{28} \mathrm{Br}_{4} \mathrm{Mg}_{2} \mathrm{O}_{6}$ \\
\hline Mol. Wt. & 528.03 & 893.32 & 636.58 \\
\hline Crystal system & Monoclinic & Monoclinic & Monoclinic \\
\hline Space group & $P 2_{1} / c$ & $P 2_{1} / c$ & $P 2_{1} / c$ \\
\hline$a / \AA$ & $10.210(5)$ & $11.0198(3)$ & $10.651(6)$ \\
\hline$b / \AA$ & $7.5150(3)$ & $7.8984(2)$ & $7.803(11)$ \\
\hline$c / \AA$ & $14.2800(7)$ & $14.8038(4)$ & $14.476(7)$ \\
\hline$\beta /{ }^{\circ}$ & $110.758(4)$ & $110.505(2)$ & $110.42(4)$ \\
\hline$V / \AA^{3}$ & $1029.67(17)$ & $1207.87(10)$ & $1127.5(18)$ \\
\hline$Z$ & 2 & 2 & 2 \\
\hline$(\mu-X)-M / \AA$ & $2.3819(11), 2.4916(13)$ & $2.6647(8), 2.8296(9)$ & $2.546(7), 2.822(8)$ \\
\hline$X-M / \AA$ & $2.3457(14)$ & $2.7191(9)$ & $2.584(8)$ \\
\hline$M-M / \AA$ & 3.6 & 4.1 & 3.9 \\
\hline$M-\mathrm{O} 1($ or 3$) / \AA$ & $2.160(3), 2.159(3)$ & $2.110(5), 2.104(5)$ & $2.105(16), 2.115(15)$ \\
\hline$M-\mathrm{O} 2 / \AA$ & $2.144(3)$ & $2.058(4)$ & $2.089(14)$ \\
\hline$M-X 1-M{ }^{\circ}$ & $95.04(4)$ & $93.87(3)$ & $94.5(2)$ \\
\hline$X 1-M-X 1 /{ }^{\circ}$ & $84.96(4)$ & $86.13(3)$ & $85.5(2)$ \\
\hline$X 1-M-X 2 / \circ$ & $95.37(4), 178.74(5)$ & $93.27(3), 178.75(4)$ & $96.2(2), 177.4(2)$ \\
\hline Ionic radii of $M / \mathrm{pm}$ & $57 \mathrm{LS}, 74 \mathrm{HS}$ & 70 & 72 \\
\hline Ionic radii of $X / \mathrm{pm}$ & 181 & 220 & 196 \\
\hline BVS & 1.97 & 2.15 & 2.15 \\
\hline
\end{tabular}


by $3.4 \AA$. The anionic unit B consists of two cobalt cations, $\mathrm{Co} 2$ and $\mathrm{Co} 2 "$ " $"=\mathbf{1}-\boldsymbol{x}, \mathbf{1}-\boldsymbol{y}, \mathbf{1}-\boldsymbol{z})$, linked to each other by two $\mu$-bridging chloride anions, $\mathrm{Cl} 2$ and $\mathrm{Cl} 2 "$ (Figure 12). In the geometrical middle of the so formed rhombus, an inversion center is found. The tetrahedral coordination of each cation is completed by two chloride atoms, the $\mathrm{Co}-\mathrm{Cl}$ distances are 2.3344(9) $\AA$ for $\mathrm{Cl} 2,2.218(1)$ for $\mathrm{Cl} 3$, and 2.226(1) for $\mathrm{Cl} 4$, which is shorter than in the cation $\mathrm{A}$, as expected for the lower coordination number of the cobalt ions in $\mathrm{B}$. The angle between the two $\mu-\mathrm{Cl}$ is $95.24(3)^{\circ}$, the angles $\mathrm{Cl} 2-\mathrm{Co} 2-\mathrm{Cl}$ are $113.87(4)^{\circ}$ for $\mathrm{Cl} 3$ and $110.49(3)^{\circ}$ for $\mathrm{Cl} 4$, the angle $\mathrm{Cl} 3-\mathrm{Co} 2-$ $\mathrm{Cl} 4$ is $116.31(4)^{\circ}$. In the anionic part $\mathrm{B}$ the cobalt cations are separated by $3.16 \AA$.
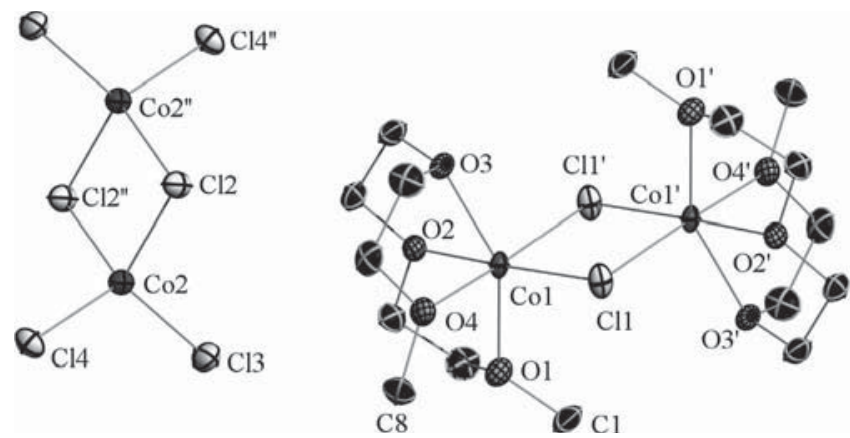

Figure 12. View of the molecular structure of $\mathbf{1 1}$ with polyhedral, hydrogen atoms are omitted for clarity, $50 \%$ probability $('=-x,-y, 1-$ $z ; "=1-x, 1-y, 1-z)$.

The bond valence sum method gives values of 2.04 for Col and 2.07 for $\mathrm{Co} 2$, which indicates a good-coordination of the metal cations [48].

A similar structure has been published by Kinneging, but this structure is composed by three moieties: A, B and B' [76]. The molecule $\mathrm{A}$ is the same than in our compound $\mathbf{1 1}$ but the molecules $\mathrm{B}$ and $\mathrm{B}^{\prime}$ are $\mathrm{SbCl}_{6}{ }^{-}$. For compound 11, as for compounds $\mathbf{1}$ and $\mathbf{2}$, tetrahedral and octahedral coordination for cobalt is observed.

With $\mathrm{NiI}_{2}$, we expected a similar compound as compounds 10 or $\mathbf{1 1}$, but the product was surprising.

\section{Compound cis- $\left[\left(\mathrm{NiI}_{2}\right)_{2}(\text { triglyme })\right]_{n}(12)$}

The dissolution of $\mathrm{NiI}_{2}$ in dried triglyme yields compound 12, which crystallizes in the orthorhombic space group Pbcn. In contrast to previously published compounds $[8,12]$ and compound 11, one molecule of triglyme in $\mathbf{1 2}$ coordinates to two different nickel ions, each nickel atom being hexacoordinated by two iodide atoms and four oxygen atoms, delivered two by two from two different triglyme ligands. The coordination arrangement of a nickel ion can thus be described as distorted octahedral with two iodide ions arranged in cis positions and four oxygen atoms (Figure 13). The I1-Ni1-O $1^{\text {ii }}$ and $\mathrm{O} 2-$ $\mathrm{Ni1}-\mathrm{O} 2^{\mathrm{ii}}$ angles are far from linear with values of $171.1(2)^{\circ}$ and $162.4(4)^{\circ}$, respectively ( $\mathrm{ii}=-x, y, 1 / 2-z$ ). This is partially due to the bite angle of the triglyme ligands, which is $79.4(3)^{\circ}$. The angle between the two iodide ions $\mathrm{I} 1$ and $\mathrm{I}^{\mathrm{ii}}$ is with $95.74(7)^{\circ}$ larger than the expected $90^{\circ}$ for a perfect octahedron. The Ni-O bonds are 2.121(7) and 2.124(7) $\AA$ long for Ni1$\mathrm{O} 1$ and Ni1-O2, respectively, the Ni-I bonds are 2.684(1) $\AA$ long. For the first time in our series of compounds, the polyether ligand adopts a bridging function between the metal ions, initiating the formation of a one-dimensional coordination polymer. Whereas within a chain all iodide ions point into the same direction, inducing a dipole moment perpendicular to the chain propagation, their orientation is opposite in the neighbor chains. An overall apolar compound results from such an arrangement.

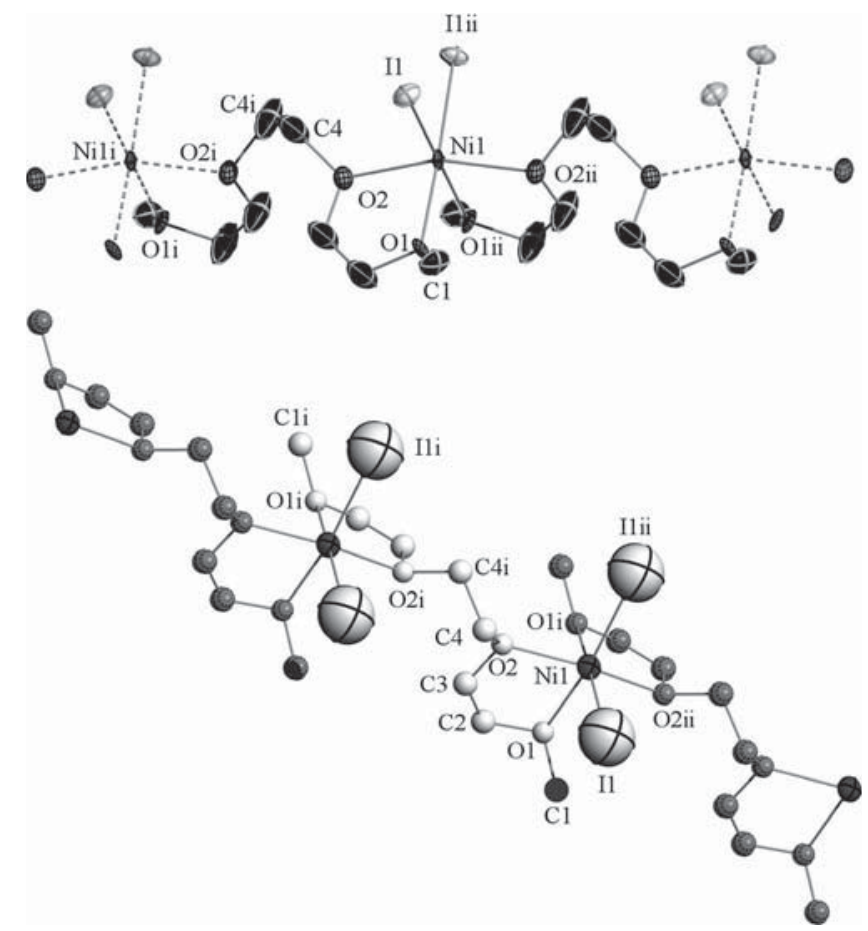

Figure 13. View of the molecular structure of 12, hydrogen atoms are omitted for clarity, $50 \%$ probability $(\mathrm{I}=-1-x, y, 1 / 2-z$; ii $=-x, y, 1 / 2-z)$.

The literature has some examples of transition metal complexes of triglyme based on $\mathrm{CdCl}_{2}$ or $\mathrm{CdBr}_{2}$, in which chains of $\mathrm{Cd}-X$ are connected by triglyme. For $\mathrm{CdI}_{2}$, Hines has obtained a molecular $\mathrm{CdI}_{2}$ with one triglyme [77]. Bridging properties of glyme were also described for alkaline earth metal cluster compounds [42], but is a very rare phenomenon. This is very likely due to energetic reasons. Thus, entropically, it is more favorable to form individual entities rather than a polymeric structure. Compound $\mathbf{1 2}$ is thus the first example of a coordination polymer of $\mathrm{NiI}_{2}$ and also the first with a polymerization not due to the halide, but based on the bridging function of triglyme.

\section{Conclusions}

We synthesized a series of polyether adducts of transition metal halides, five with glyme, five with diglyme and two with triglyme. For such polyether adducts, 1, 2, and $\mathbf{1 1}$ are the first examples of the two coordination modes of $\mathrm{Co}^{2+}$ with $\mathrm{O}$-do- 
nors and halides present within one compound. Compound 3 confirmed the previously described analyses of Ward for a compound, which was not structurally characterized before, whereas $\mathbf{4}$ is a new example of a tetracoordinate zinc halide. For the diglyme compounds, $\mathbf{6 , 7}$ and $\mathbf{8}$ are new examples of pentacoordinate arrangement of cobalt, zinc and mercury metal ions, which is not common with iodides and oxygen atoms as donor atoms. Compound $\mathbf{8}$ is an intermediate to halide-bridged transition metal diglyme adducts as exemplified by $\mathbf{9}$ and $\mathbf{1 0}$. Compound $\mathbf{1 2}$ is the first example 1D coordination polymer of triglyme. We are currently testing these compounds as starting materials for the generation of new cluster aggregates.

\section{Experimental Section}

General: All experiments were carried out under an inert argon atmosphere, using Schlenk technique [43]. Glyme was dried with Na/benzophenone and distilled under argon and diglyme and triglyme were bought dried and stocked over molecular sieve.

$\left.\left[\mathbf{C o}(\boldsymbol{\mu}-\mathbf{C l})_{2} \mathbf{C o C l}_{\mathbf{2}} \text { (glyme }\right)_{2}\right]$ (1): $\mathrm{CoCl}_{2}(0.165 \mathrm{~g}, 1.27 \mathrm{mmol})$ was dried for 1 hour under vacuum at $300{ }^{\circ} \mathrm{C}$ and afterwards dissolved in dried glyme $(25 \mathrm{~mL})$ whilst heating to reflux under magnetic stirring for 1 h. Afterwards, the solution was filtered under argon and the solution was slowly evaporated at 400 mbar. Blue single-crystals of $\mathbf{1}$ suitable for X-ray analysis grew in a yield of $20 \%$, the low evaporation temperature of glyme and the strong hydrophilic character of $\mathrm{CoCl}_{2}$ could explain the values found for elemental analysis. Elemental Analysis: (the found mass corresponds to partially decomposed and hydrated compound $1+0.53 \mathrm{CoCl}_{2}+1.24 \mathrm{H}_{2} \mathrm{O}$ ) calcd. C $18.09 \mathrm{H} 4.27$; found $\mathrm{C}$ 18.10 H 4.27. IR: $\tilde{v}=3364$ (w), 3026 (sh), 2944 (m), 2853 (sh), 2050 (w), 1619 (m), 1449 (m), 1362(sh), 1277 (sh), 1240(m), 1187 (sh), 1089 (m), 1041 (s), 859 (sh), 827 (s) $\mathrm{cm}^{-1}$.

cis- $\left[\mathrm{CoI}_{2}\left(\mathrm{H}_{2} \mathbf{O}\right)_{\mathbf{2}}\left(\text { glyme }_{2}\right]^{2+}\left[\mathrm{CoI}_{4}\right]^{2-}\right.$ (2): $\mathrm{CoI}_{2}(0.57 \mathrm{~g}, 1.82 \mathrm{mmol})$ was dried for 1 hour under vacuum at $300{ }^{\circ} \mathrm{C}$ and afterwards dissolved in dried glyme $(20 \mathrm{~mL})$ whilst heating to reflux under magnetic stirring for $1 \mathrm{~h}$. Afterwards, the solution was filtered under argon and the solution was slowly evaporated at room temperature. Green single-crystals of 2 suitable for X-ray analysis grew in some weeks with a yield of $10 \%$. Elemental Analysis: (the found mass corresponds to partially hydrated compound $2+2.25 \mathrm{H}_{2} \mathrm{O}$ ) calcd, C 10.89 , H $3.25 \%$; found C 10.82, H $3.16 \%$. IR: $\tilde{v}=3293$ (w), 2943 (m), 2834 (sh), 1621 (m), $1453(\mathrm{~m}), 1365$ (sh), 1274 (sh), 1241 (sh), 1188 (sh), 1090 (m), 1038 s), $858(\mathrm{sh}) 825(\mathrm{~s}), 660(\mathrm{w}) \mathrm{cm}^{-1}$.

cis-[NiI (glyme $\left._{2}\right]$ (3): $\mathrm{NiI}_{2}(0.129 \mathrm{~g}, 0.41 \mathrm{mmol})$ was dried for 1 hour under vacuum at $300{ }^{\circ} \mathrm{C}$ and afterwards dissolved in freshly dried and distilled glyme $(20 \mathrm{~mL})$ whilst heating to reflux under magnetic stirring for $1 \mathrm{~h}$. Afterwards, the solution was concentrated and the mixture was left at $4{ }^{\circ} \mathrm{C}$. Orange single-crystals of $\mathbf{3}$ suitable for X-ray analysis grew in one week with a yield of $70 \%$, the low evaporation temperature of glyme could explain the values found for elemental analysis. Elemental Analysis: (the found mass corresponds to partially decomposed compound $\mathbf{3}+0.113 \mathrm{NiI}_{2}$ ) calcd. C 18.20, H $3.82 \%$; found C 18.20 H $3.80 \%$. IR: $\tilde{v}=2929(\mathrm{~m}), 2852(\mathrm{sh}), 1605(\mathrm{~m}), 1453(\mathrm{~m})$, 1364 (sh), 1286 (sh), $1243(\mathrm{~m}), 1209$ (sh), 1188 (sh), 1086 (m), 1040 (s), 1017 (sh), 984 (sh), 852 (s) $\mathrm{cm}^{-1}$.

[ZnI 2 (glyme)] (4): $\mathrm{ZnI}_{2}(0.119 \mathrm{~g}, 0.37 \mathrm{mmol})$ was dried for 1 hour under vacuum at $300{ }^{\circ} \mathrm{C}$ and afterwards dissolved in freshly dried and distilled glyme $(20 \mathrm{~mL})$ whilst heating to reflux under magnetic stir- ring for $30 \mathrm{~min}$. Afterwards, the solution was concentrated, heptane was added and the mixture was left at $4{ }^{\circ} \mathrm{C}$. Colorless single-crystals of 4 suitable for X-ray analysis grew in one week with a yield of $90 \%$. Elemental Analysis: (4 + 0.58glyme) calcd. C 16.52 H $3.37 \%$; found C 16.49 H $3.46 \%$. IR: $\tilde{v}=2923$ (m), $2852(\mathrm{sh}), 2829(\mathrm{~s}), 1450$ (m), 1368 (sh), 1270 (sh), 1236 (sh), 1190 (sh), 1159 (sh), 1129 (sh), 1081 (s), 1032 (s), 1001 (sh), 852 (s), 817 (m), 722 (sh) $\mathrm{cm}^{-1} .{ }^{1} \mathbf{H}$ NMR $\left(\mathrm{CDCl}_{3}\right): \delta=3.23 \mathrm{ppm}(\mathrm{s}, 6 \mathrm{H}), 3.42(\mathrm{~s}, 4 \mathrm{H})$.

[ $\mathrm{HgCl}_{\mathbf{2}}$ (glyme)] (5): $\mathrm{HgCl}_{2}(0.115 \mathrm{~g}, 0.42 \mathrm{mmol})$ was dried for 1 hour under vacuum at $300{ }^{\circ} \mathrm{C}$ and afterwards dissolved in freshly dried and distilled glyme $(4 \mathrm{~mL})$ whilst heating to reflux under magnetic stirring for $30 \mathrm{~min}$. Afterwards, the solution was concentrated and the mixture was left at $4{ }^{\circ} \mathrm{C}$. Colorless single-crystals of 5 suitable for X-ray analysis grew in some days with a yield of $70 \%$. IR: $\tilde{v}=2998$ (s), 2946 (w), 2918 (w), 2886 (w), 2848 (sh), 2824 (sh), 1471 (s), 1454 (sh), 1412 (sh), 1368 (s), $1286(\mathrm{sh}), 1242(\mathrm{~m}), 1192(\mathrm{~m}), 1156(\mathrm{sh}), 1068$ (s), $1015(\mathrm{~m}), 847$ (s), 839 (s), $685(\mathrm{w}) \mathrm{cm}^{-1}$.

[CoI (diglyme) $_{\mathbf{2}}$ (6): $\mathrm{CoI}_{2}(0.57 \mathrm{~g}, 1.82 \mathrm{mmol})$ was dried for 1 hour under vacuum at $300{ }^{\circ} \mathrm{C}$ and afterwards dissolved in dried diglyme $(20 \mathrm{~mL})$ whilst heating to reflux under magnetic stirring for $1 \mathrm{~h}$. Afterwards, the solution was filtered under argon and the solution was slowly evaporated at $2 \cdot 10^{-2}$ mbar. Blue single-crystals of $\mathbf{6}$ suitable for $\mathrm{X}$-ray analysis grew in a yield of $80 \%$. Elemental Analysis: calcd. C 16.13, H $3.16 \%$; found C 16.11 H $3.27 \%$. IR: $\tilde{v}=3006$ (sh), 2931 (w), 2886 (sh), 2831 (s), 1609 (m), 1448 (m), 1239 (sh), 1195 (sh), 1080 (m), 1043 (m), 998 (m), 946 (s), 866 (m),827 (sh), 814 (h) cm $\mathrm{cm}^{-1}$.

[ZnI $\mathbf{Z}_{\mathbf{2}}$ (diglyme)] (7): $\mathrm{ZnI}_{2}(0.200 \mathrm{~g}, 0.62 \mathrm{mmol})$ was dried for 1 hour under vacuum at $300{ }^{\circ} \mathrm{C}$ and afterwards dissolved in dried diglyme $(25 \mathrm{~mL})$ whilst heating to reflux under magnetic stirring for $30 \mathrm{~min}$. Afterwards, the solution was filtered and left at $-25^{\circ} \mathrm{C}$. Colorless single-crystals of 7 suitable for X-ray analysis grew in some weeks with a yield of $70 \%$. Elemental Analysis: calcd. C 15.90, H $3.11 \%$; found C 16.05 H $3.04 \%$. IR: $\tilde{v}=3000$ (sh), 2928 (w), 2886 (sh), 2831 (s), 1596 (m), 1448 (m), 1346 (sh), 1277 (sh), 1242 (sh), 1197 (sh), 1087 (m), 1055 (m), 1002 (m), 948 (s), 867 (m), 831 (sh), 818 (h) cm $\mathrm{cm}^{-1}$

[ $\mathbf{H g I}_{2}$ (diglyme)] (8): $\mathrm{HgI}_{2}(0.15 \mathrm{~g}, 0.44 \mathrm{mmol})$ was dried for 1 hour under vacuum at $200{ }^{\circ} \mathrm{C}$ and afterwards dissolved in dried diglyme $(15 \mathrm{~mL})$ whilst heating to reflux under magnetic stirring for $1 \mathrm{~h}$. Afterwards, the solution was filtered under argon and the solution was slowly evaporated at $2.10^{-2}$ mbar. After one night at $4{ }^{\circ} \mathrm{C}$, we obtained colorless single-crystals of $\mathbf{8}$ suitable for X-ray analysis with a yield of $50 \%$. IR: $\tilde{v}=3000$ (sh), 2926 (w), 2885 (sh), 2833 (s), 2360 (sh), 1577 (m), 1448 (m), 1374 (sh), 1347 (sh), 1279 (sh), 1242 (m), 1197 (sh), 1089 (m), 1057 (m), 1002 (m), 947 (s), 861 (m), 830 (sh), 819 (h) $\mathrm{cm}^{-1}$.

$[\mathrm{CoCl}(\mu-\mathrm{Cl})(\text { diglyme })]_{2}$ (9): $\mathrm{CoCl}_{2}(0.15 \mathrm{~g}, 1.15 \mathrm{mmol})$ was dried for 1 hour under vacuum at $300{ }^{\circ} \mathrm{C}$ and afterwards dissolved in dried diglyme $(25 \mathrm{~mL})$ whilst heating to reflux under magnetic stirring for 1 h. Afterwards, the solution was filtered under argon and the solution was slowly evaporated at $2.10^{-2}$ mbar. Blue single-crystals of 9 suitable for X-ray analysis grew in a yield of $60 \%$. The high hydrophilic character of $\mathrm{CoCl}_{2}$ and a too long drying of the sample could explain the elemental analysis. Elemental Analysis: (the found mass corresponds to partially decomposed compound $9+0.117 \mathrm{CoCl}_{2}$ ) calcd. C 26.50, H $5.36 \%$; found C 26.53 H $5.20 \%$. IR: $\tilde{v}=2940(\mathrm{~m}), 2890$ (m), 1725 (sh), $1610(\mathrm{w}), 1451$ (m), 1344 (sh), 1282 (s), 1266 (sh), 1247 (m), 1234 (sh), 1193 (m), 1111 (sh), 1081 (h), 1055 (h), 1010 (h), 952 (m), 8667 (m), 837 (m), 827 (sh), 743 (w) $\mathrm{cm}^{-1}$. 
[NiI( $\boldsymbol{\mu}$-I)(diglyme) $]_{2}$ (10): $\mathrm{NiI}_{2}(0.200 \mathrm{~g}, 0.64 \mathrm{mmol})$ was dried for 1 hour under vacuum at $300{ }^{\circ} \mathrm{C}$ and afterwards dissolved in dried diglyme $(25 \mathrm{~mL})$ whilst heating to reflux and under magnetic stirring for $30 \mathrm{~min}$. Afterwards, the solution was filtered and left at $-25^{\circ} \mathrm{C}$. Orange single-crystals of $\mathbf{1 0}$ suitable for X-ray analysis grew in some days with a yield of $70 \%$. Elemental Analysis: (the found mass corre-

Table 5. Crystallographic data and details of the crystal structure determination of compounds 1-6.

\begin{tabular}{|c|c|c|c|c|c|c|}
\hline & 1 & 2 & 3 & 4 & 5 & 6 \\
\hline Formula & $\mathrm{C}_{8} \mathrm{H}_{20} \mathrm{Cl}_{4} \mathrm{Co}_{2} \mathrm{O}_{8}$ & $\mathrm{C}_{8} \mathrm{H}_{24} \mathrm{I}_{4} \mathrm{Co}_{2} \mathrm{O}_{6}$ & $\mathrm{C}_{8} \mathrm{H}_{20} \mathrm{I}_{2} \mathrm{NiO}_{4}$ & $\mathrm{C}_{4} \mathrm{H}_{10} \mathrm{I}_{2} \mathrm{O}_{2} \mathrm{Zn}$ & $\mathrm{C}_{4} \mathrm{H}_{10} \mathrm{Cl}_{2} \mathrm{HgO}_{2}$ & $\mathrm{C}_{6} \mathrm{H}_{14} \mathrm{I}_{2} \mathrm{CoO}_{3}$ \\
\hline $\mathrm{M} / \mathrm{g} \cdot \mathrm{mol}^{-1}$ & 893.32 & 841.76 & 492.7 & 409.32 & 361.61 & 446.92 \\
\hline Crystal system & monoclinic & monoclinic & monoclinic & orthorhombic & monoclinic & orthorhombic \\
\hline Space group & $C 2 / c($ Nr. 15$)$ & $P 2_{1} / c$ (Nr. 14) & $P 2_{1} / c($ Nr. 14$)$ & Pbcn (Nr. 60) & $C 2 / c($ Nr. 15$)$ & $P_{n a 2_{1}}$ (Nr. 33) \\
\hline \multirow[t]{4}{*}{ Unit cell / $/$ or $^{\circ}$} & $a=13.687(4)$ & $a=10.7910(44)$ & $a=13.1000(6)$ & $a=13.3660(6)$ & $a=14.8792(17)$ & $a=14.3582(3)$ \\
\hline & $b=9.9885(14)$ & $b=11.6797(3)$ & $b=7.7510(2)$ & $b=7.2700(7)$ & $b=7.2358(6)$ & $b=9.9766(3)$ \\
\hline & $c=12.883(3)$ & $c=17.8873(6)$ & $c=30.3250$ & $c=10.744(1)$ & $c=8.2891(10)$ & $c=8.7439(3)$ \\
\hline & $\beta=101.124(19)$ & $\beta=90.265(3)$ & $\beta=90.233(4)$ & & $\beta=99.268(10)$ & \\
\hline$V / \AA^{3}$ & $1728.2(7)$ & $2254.41(1)$ & $3074.24(7)$ & $1044.00(2)$ & $880.78(16)$ & $1252.53(1)$ \\
\hline$Z$ & 2 & 4 & 8 & 4 & 4 & 4 \\
\hline$\rho$ calcd. $/ \mathrm{Mg} \cdot \mathrm{m}^{-3}$ & 1.691 & 2.48 & 2.13 & 2.60 & 2.727 & 2.370 \\
\hline$F(000)$ & 888 & 1543.9 & 1871.8 & 743.9 & 656 & 528 \\
\hline$T / \mathrm{K}$ & 150 & 150 & 150 & 150 & 150 & 150 \\
\hline$\lambda / \AA$ & 0.71073 & 0.71073 & 0.71073 & 0.71073 & 0.71073 & 0.71073 \\
\hline$\mu\left(\mathrm{Mo}-K_{\alpha}\right) / \mathrm{mm}^{-1}$ & 0.120 & 0.120 & 0.120 & 0.120 & 0.120 & 0.120 \\
\hline $\min <\theta<\max$ & $2.5 ; 22.7$ & $2.1 ; 20$ & $3.3 ; 22.7$ & $3.2 ; 22.7$ & $3.14 ; 22.50$ & $2.5 ; 29.2$ \\
\hline reflections & 1152 & 2070 & 13931 & 4371 & 556 & 23574 \\
\hline unique & 1152 & 2070 & 4089 & 677 & 556 & 3372 \\
\hline observed & 320 & 1660 & 3738 & 664 & 533 & 2958 \\
\hline $\begin{array}{l}\text { parameters re- } \\
\text { fined }\end{array}$ & 85 & 185 & 279 & 43 & 43 & 111 \\
\hline GOOF & 0.591 & 0.817 & 1.096 & 1.633 & 1.075 & 1.079 \\
\hline$R_{1}$ for $I>2 \sigma(I)$ & 0.065 & 0.035 & 0.033 & 0.051 & 0.084 & 0.052 \\
\hline$w R_{2}$ for $I>2 \sigma(I)$ & 0.159 & 0.080 & 0.084 & 0.168 & 0.193 & 0.129 \\
\hline$R_{1}$ for all data & 0.185 & 0.046 & 0.037 & 0.062 & 0.085 & 0.062 \\
\hline$w R_{2}$ for all data & 0.197 & 0.083 & 0.087 & 0.183 & 0.196 & 0.135 \\
\hline
\end{tabular}

Table 6. Crystallographic data and details of the crystal structure determination of compounds 8-12.

\begin{tabular}{|c|c|c|c|c|c|c|}
\hline & 7 & 8 & 9 & 10 & 11 & 12 \\
\hline Formula & $\mathrm{C}_{6} \mathrm{H}_{14} \mathrm{I}_{2} \mathrm{ZnO}_{3}$ & $\mathrm{C}_{6} \mathrm{H}_{14} \mathrm{HgI}_{2} \mathrm{O}_{3}$ & $\mathrm{C}_{12} \mathrm{H}_{28} \mathrm{Cl}_{4} \mathrm{Co}_{2} \mathrm{O}_{6}$ & $\mathrm{C}_{12} \mathrm{H}_{28} \mathrm{I}_{4} \mathrm{Ni}_{2} \mathrm{O}_{6}$ & $\mathrm{C}_{16} \mathrm{H}_{36} \mathrm{Cl}_{8} \mathrm{Co}_{4} \mathrm{O}_{8}$ & $\mathrm{C}_{16} \mathrm{H}_{36} \mathrm{I}_{4} \mathrm{Ni}_{2} \mathrm{O}_{8}$ \\
\hline $\mathrm{M} / \mathrm{g} \cdot \mathrm{mol}^{-1}$ & 453.39 & 588.56 & 528.03 & 893.32 & 875.81 & 981.14 \\
\hline Crystal system & orthorhombic & triclinic & monoclinic & monoclinic & monoclinic & orthorhombic \\
\hline Space group & $\operatorname{Pna2}_{1}$ (Nr. 33) & $P \overline{1}($ Nr. 2) & $P 2_{1} / c($ Nr. 14$)$ & $P 2_{1} / c($ Nr. 14$)$ & $P 2_{1} / c(\mathrm{Nr} 14)$ & Pbcn (Nr. 60) \\
\hline \multirow[t]{6}{*}{ Unit cell / $\AA$ or ${ }^{\circ}$} & $a=14.4305(2)$ & $a=7.5607(4)$ & $a=10.2610(45)$ & $a=11.0180(3)$ & $a=7.282(4)$ & $a=7.0402(4)$ \\
\hline & $b=10.0024(4)$ & $b=8.2738(5)$ & $b=7.5150(3)$ & $b=7.9050(2)$ & $b=14.9930(6)$ & $b=13.6015(14)$ \\
\hline & $c=8.7120$ & $c=12.0869(7)$ & $c=12.883(3)$ & $c=14.8010(4)$ & $c=15.0160(8)$ & $c=14.4478(3)$ \\
\hline & & $\alpha=108.041(4)$ & & & & \\
\hline & & $\beta=89.917(4)$ & $\beta=110.758(4)$ & $\beta=110.490(2)$ & $\beta=91.840(4)$ & \\
\hline & & $\gamma=112.091(4)$ & & & & \\
\hline$V / \AA^{3}$ & $1207.57(6)$ & & $1029.67(17)$ & $1207.57(6)$ & 1638.59 & $1383.48(12)$ \\
\hline Z & 2 & 2 & 2 & 2 & 4 & 2 \\
\hline$\rho$ calcd. $/ \mathrm{Mg} \cdot \mathrm{m}^{-3}$ & 2.457 & 2.960 & 1.70 & 2.457 & 2.677 & 2.355 \\
\hline$F(000)$ & 832 & 520 & 539.9 & 832 & 880 & 928 \\
\hline$T / \mathrm{K}$ & 150 & 150 & 150 & 150 & 150 & 150 \\
\hline$\lambda / \AA$ & 0.71073 & 0.71073 & 0.71073 & 0.71073 & 0.71073 & 0.71073 \\
\hline$\mu\left(\mathrm{Mo}-K_{\alpha}\right) / \mathrm{mm}^{-1}$ & 0.120 & 0.120 & 0.120 & 0.120 & 0.120 & 0.120 \\
\hline $\min <\theta<\max$ & $2.5 ; 29.2$ & $1.79 ; 24.99$ & $2.1 ; 25.6$ & $2.9 ; 31.9$ & $3.04 ; 24$ & $3.26 ; 27.92$ \\
\hline reflections & 3380 & 8855 & 1908 & 4128 & 1846 & 1617 \\
\hline unique & 3380 & 2316 & 1908 & 4128 & 1846 & 1617 \\
\hline observed & 2473 & 2316 & 1460 & 3626 & 1625 & 527 \\
\hline $\begin{array}{l}\text { parameters re- } \\
\text { fined }\end{array}$ & 112 & 111 & 111 & 111 & 165 & 58 \\
\hline GOOF & 0.710 & 1.080 & 0.995 & 1.171 & 1.006 & 0.465 \\
\hline$R_{1}$ for $I>2 \sigma(I)$ & 0.040 & 0.0637 & 0.034 & 0.056 & 0.026 & 0.0391 \\
\hline$w R_{2}$ for $I>2 \sigma(I)$ & 0.111 & 0.1585 & 0.100 & 0.146 & 0.061 & 0.519 \\
\hline$R_{1}$ for all data & 0.058 & 0.0791 & 0.051 & 0.062 & 0.032 & 0.1550 \\
\hline$w R_{2}$ for all data & 0.118 & 0.1651 & 0.105 & 0.150 & 0.064 & 0.0790 \\
\hline
\end{tabular}


sponds to partially decomposed compound $\mathbf{1 0}+0.45 \mathrm{NiI}_{2}$ ) calcd. C 19.94, H $3.90 \%$; found C 19.97 H $3.91 \%$. IR: $\tilde{v}=3298$ (w), 2925 (m), 2853 (sh), 1587 (sh), 1460 (m), 1376 (s), 1340 (s), 1278 (s), 1261 (s), $1240(\mathrm{~m}), 1202$ (s), 1162 (s), 1105 (m), 1076 (h), 1046 (h), 1002 (h), 951 (m), 864 (h), 829 (h), $819(\mathrm{~m}), 758(\mathrm{~s}) \mathrm{cm}^{-1}$.

$[\mathrm{Co}(\mu-\mathrm{Cl})$ (triglyme) $)]_{2}{ }^{2+}\left[\mathrm{CoCl}_{2}(\boldsymbol{\mu}-\mathrm{Cl})\right]_{2}{ }^{2-} \quad$ (11): $\quad \mathrm{CoCl}_{2} \quad(0.220 \mathrm{~g}$, $1.69 \mathrm{mmol}$ ) was dried for 1 hour under vacuum at $300{ }^{\circ} \mathrm{C}$ and afterwards dissolved in dried triglyme $(15 \mathrm{~mL})$ whilst heating to reflux under magnetic stirring for $1 \mathrm{~h}$. Afterwards, the solution was filtered under argon and the solution was concentrated and let at room temperature. Blue single-crystals of $\mathbf{1 1}$ suitable for $\mathrm{X}$-ray analysis grew in two weeks with a yield of $10 \%$, the high hydrophilic character of $\mathrm{CoCl}_{2}$ could explain the elemental analysis. Elemental Analysis: $(11+$ 1.12 triglym) calcd. C 27.85 , H $5.40 \%$; found C $27.87 \mathrm{H} 5.26 \%$. IR: $\tilde{v}=3336(\mathrm{w}), 2946(\mathrm{~m}), 2894(\mathrm{sh}), 1639$ (s), 1489 (sh), 1448 (sh), 1351 (s), 1300 (sh), 1244 (sh), 1198 (sh), 1102 (m), 1083 (m), 1051 (m), 1029 (m), 1011 (m), 939 (s), 917 (m), 861 (m), 832 (m), 772 (sh) $\mathrm{cm}^{-1}$.

cis-[NiI (triglyme) $_{n}$ (12): $\mathrm{NiI}_{2}(0.129 \mathrm{~g}, 0.41 \mathrm{mmol})$ was dried for 1 hour under vacuum at $300{ }^{\circ} \mathrm{C}$ and afterwards dissolved in dried triglyme $(25 \mathrm{~mL})$ whilst heating to reflux under magnetic stirring for 1 h. Afterwards, the solution was filtered under argon and the solution was concentrated and let at room temperature. Yellow-orange singlecrystals of $\mathbf{1 2}$ suitable for X-ray analysis grew in three weeks in a yield of $20 \%$. Elemental Analysis: $(\mathbf{1 2}+2.74$ triglyme $)$ calcd. C 36.69 , H $6.93 \%$; found C 36.75, H $6.65 \%$. IR: $\tilde{v}=3020(\mathrm{sh}), 2963(\mathrm{sh})$, 2928 (m), 2874 (w), 2823 (s), 1609 (sh), 1438 (s), 1377 (sh), 1349 (s), 1287 (s), 1236 (s), 1189 (s), 1133 (s), 1105 (m), 1071 (m), 1035 (m), $1012(\mathrm{~m}), 984(\mathrm{~m}), 909(\mathrm{~m}), 844(\mathrm{~m}), 803(\mathrm{~s}) \mathrm{cm}^{-1}$.

Single Crystal X-ray Structures: All crystals were mounted on loops and all geometric and intensity data were taken from one single crystal. Data collection using Mo- $K_{\alpha}$ radiation $(\lambda=0.71073 \AA)$ was performed at $150 \mathrm{~K}$ on a STOE IPDS-II diffractometer equipped with an Oxford Cryosystem open flow cryostat [44]. Absorption correction was partially integrated in the data reduction procedure [45]. The structure was solved by SIR 2004 and refined using full-matrix least-squares on $F 2$ with the SHELX-97 package [46, 47]. All heavy atoms could be refined anisotropically. Hydrogen atoms were introduced as fixed contributors when a residual electronic density was observed near their expected positions. Table 5 (compounds 1-7) and Table 6 (compounds 8-12) contain the crystallographic data and details of the structure analyses.

Crystallographic data (excluding structure factors) for the structures in this paper have been deposited with the Cambridge Crystallographic Data Centre, 12 Union Road, Cambridge CB21EZ, UK. Copies of the data can be obtained on quoting the depository numbers CCDC749980 (1), -749981 (2), -749982 (3), -749983 (4), -749984 (5), -749985 (6), -749986 (7), -749987 (8), -749988 (9), -749989 (10), -749990 (11), and -749991 (12) (Fax: +44-1223-336-033; E-Mail: deposit@ccdc.cam.ac.uk).

Supporting Information (See footnote on the first page of this article): Some pictures and additional crystallographic tables.

\section{Acknowledgement}

The authors thank the Swiss National Science Foundation as well as FriMat, the University of Fribourg and the Adolphe Merke Stiftung for most generous support. We are grateful to Professor Karl Wieghardt from MPI Mühlheim, Germany, for magnetic measurements of compound 9.

\section{References}

[1] K. M. Fromm, E. D. Gueneau, Polyhedron 2004, 23, 1479-1504.

[2] K. M. Fromm, Angew. Chem. Int. Ed. 1998, 36, 2799-2801.

[3] K. M. Fromm, Chem. Commun. 1999, 1659-1660.

[4] K. M. Fromm, E. D. Gueneau, H. Goesmann, Chem. Commun. 2000, 2187-2188.

[5] K. M. Fromm, H. Goesmann, G. Bernardinelli, Polyhedron 2000, 19, 1783-1789.

[6] K. M. Fromm, H. Goesmann, Acta Crystallogr., Sect. C 2000, 56, $1179-1180$.

[7] K. M. Fromm, G. Bernardinelli, M. J. Mayor-Lopez, H. Goesmann, Z. Anorg. Allg. Chem. 2000, 626, 1685-1691.

[8] K. M. Fromm, Chem. Eur. J. 2001, 7, 2236-2244.

[9] K. Fromm, G. Bernardinelli, Z. Anorg. Allg. Chem. 2001, 627, $1626-1630$

[10] K. M. Fromm, CrystEngComm 2002, 4, 318-322.

[11] K. M. Fromm, Chimia 2003, 57, 175-178.

[12] K. M. Fromm, W. Maudez, Eur. J. Inorg. Chem. 2003, 34403444.

[13] K. M. Fromm, E. D. Gueneau, G. Bernardinelli, H. Goesmann, J. Weber, M. J. Mayor-Lopez, P. Boulet, H. Chermette, J. Am. Chem. Soc. 2003, 125, 3593-3604.

[14] K. M. Fromm, E. D. Gueneau, A. Y. Robin, W. Maudez, J. Sague, R. Bergougnant, Z. Anorg. Allg. Chem. 2005, 631, 1725-1740.

[15] W. Maudez, T. Vig-Slenters, L. Mirolo, A. Fleury, K. M. Fromm, Main Group Chem. 2006, 5, 41-49.

[16] W. Maudez, D. Haeussinger, K. M. Fromm, Z. Anorg. Allg. Chem. 2006, 632, 2295-2298.

[17] D. C. Bradley, Chem. Rev. 1989, 89, 1317-1322.

[18] K. G. Caulton, L. G. Hubert-Pfalzgraf, Chem. Rev. 1990, 90, 969-995.

[19] D. C. Bradley, Adv. Inorg. Chem. Radiochemistry 1972, 15, 259322.

[20] R. C. Mehrotra, Adv. Inorg. Chem. Radiochemistry 1983, 26, 269-335.

[21] D. C. Bradley, R. C. Mehrotra, D. P. Gaur, Metal Alkoxides, Academic Press, London 1978.

[22] H. D. Lutz, Z. Anorg. Allg. Chem. 1967, 353, 207-215.

[23] H. Staeglich, E. Weiss, Chem. Ber. 1978, 111, 901-905.

[24] N. Y. Turova, B. A. Popovskin, A. V. Novoselova, Z. Anorg. Allg. Chem. 1969, 353, 207-215.

[25] K. F. Tesh, D. J. Burkley, T. P. Hanusa, J. Am. Chem. Soc. 1994, $116,2409-2417$.

[26] K. Ruhlandt-Senge, K. Davis, S. Dalal, U. Englich, M. O. Senge, Inorg. Chem. 1995, 34, 2587-2592.

[27] F. Weber, G. Wolmerhaueser, H. Sitzmann, Acta Crystallogr, Sect. E 2005, 61, m512-m513.

[28] G. W. A. Fowles, T. E. Lester, J. S. Wood, J. Inorg. Nucl. Chem. 1969, 31, 657-673.

[29] A. S. Batsanov, J. A. K. Howard, A. K. Hughes, A. J. Kingsley, Acta Crystallogr., Sect. C 1999, 55, IUC9900137.

[30] D. Wolff von Gudenberg, I. Sens, U. Mueller, B. Neumueller, K. Dehnicke, Z. Anorg. Allg. Chem. 1992, 613, 49-54.

[31] K. Dreisch, C. Andersson, C. Staalhandske, Polyhedron 1991, 10 , 2417-2421.

[32] F. Calderazzo, G. E. De Benedetto, G. Pampaloni, L. Rocchi, U. Englert, J. Organomet. Chem. 1993, 462, C10-C11.

[33] E. Hey-Hawkins, H. G. von Schnering, Z. Naturforsch. 1991, $46 b, 307-314$.

[34] W. J. Evans, T. J. Boyle, J. W. Ziller, J. Am. Chem. Soc. 1993, $115,5084-5092$.

[35] G. Pampaloni, U. Englert, Inorg. Chim. Acta 1995, 231, 167-173.

[36] A. Malassa, H. Goerls, A. Buchholz, W. Plass, M. Westerhausen, Z. Anorg. Allg. Chem. 2006, 632, 2355-2362. 
[37] V. Ripert, L. G. Hubert-Pfalzgraf, J. Vaissermann, Polyhedron 1999, 18, 1845-1851.

[38] M. G. B. Drew, J. A. Hutton, J. Chem. Soc., Dalton Trans. 1978, $1176-1179$.

[39] S. Mishra, S. Daniele, L. G. Hubert-Pfalzgraf, E. Jeanneau, Eur. J. Inorg. Chem. 2007, 2208-2215.

[40] N. Metzler, H. Noeth, M. Schmidt, A. Treitl, Z. Naturforsch. 1994, 49b, 1448-1451.

[41] P. R. Markies, G. Schat, O. S. Akkerman, F. Bickelhaupt, A. L. Spek, J. Organomet. Chem. 1992, 430, 1-13.

[42] W. Maudez, M. Meuwly, K. M. Fromm, Chem. Eur. J. 2007, 13, $8302-8316$

[43] D. F. Shriver, The Manipulation of Air-Sensitive Compounds, McGraw-Hill Series in Advanced Chemistry, 1969,pp. 299.

[44] J. Cosier, A. M. Glazer, J. Appl. Crystallogr. 1986, 19, 105-107.

[45] E. Blanc, D. Schwarzenbach, H. D. Flack, J. Appl. Crystallogr. 1991, 24, 1035-1041.

[46] M. C. Burla, R. Caliandro, M. Camalli, B. Carrozzini, G. L. Cascarano, L. De Caro, C. Giacovazzo, G. Polidori, R. Spagna, J. Appl. Crystallography. 2005, 38, 381-388.

[47] G. M. Sheldrick, SHELX-97, Program for Crystal Structure Refinement, University of Göttingen, Germany, 1997.

[48] A. S. Wills, VaList, Programm available from www.ccp14.ac.uk.

[49] P. D. Smith, J. L. Martin, J. C. Huffman, R. L. Bansemer, K. G. Caulton, Inorg. Chem. 1985, 24, 2997-3002.

[50] P. B. Hitchcock, T. H. Lee, G. J. Leigh, Inorg. Chim. Acta 2003, 348, 199-204.

[51] Y.-S. Xie, X.-T. Liu, J.-X. Yang, H. Jiang, Q.-L. Liu, C.-X. Du, Y. Zhu, Collect. Czech. Chem. Commun. 2003, 68, 2139-2149.

[52] Y. Xie, X. Liu, J. Ni, H. Jiang, Q. Liu, Appl. Organomet. Chem. 2003, 17, 650-651.

[53] Y. Xie, J. Ni, H. Jiang, Q. Liu, J. Mol. Struct. 2004, 687, 73-78.

[54] M. R. Burke, M. F. Richardson, Inorg. Chim. Acta 1983, 69, 2935

[55] G. G. Nunes, R. C. R. Bottini, D. M. Reis, P. H. C. Camargo, D. J. Evans, P. B. Hitchcock, G. J. Leigh, E. L. Sa, J. F. Soares, Inorg. Chim. Acta 2004, 357, 1219-1228.

[56] B. Brewer, N. R. Brooks, A. G. Sykes, J. Chem. Crystallogr. 2003, 33, 663-668.

[57] L. G. L. Ward, Inorg. Synth. 1971, 13, 154-164.

[58] P. A. Wender, J. P. Christy, J. Am. Chem. Soc. 2007, 129, 1340213403.
[59] J. G. Noltes, J. W. G. van den Hurk, J. Organomet. Chem. 1964, 1, 377-383.

[60] A. S. Ionkin, W. J. Marshall, D. J. Adelman, B. Bobik Fones, B. M. Fish, M. F. Schiffhauer, R. E. Spence, T. Xie, Organometallics 2008, 27, 1147-1156.

[61] C. Corbridge, J. Chem. Soc. 1956, 594.

[62] M. G. B. Drew, S. Hollis, J. Chem. Soc., Dalton Trans. 1978, 511-516.

[63] N. Louvain, N. Mercier, F. Boucher, Inorg. Chem. 2009, 48, 879888.

[64] Z. Popovic, Z. Soldin, D. Matkovic-Calogovic, G. Pavlovic, M. Rajic, G. Giester, Eur. J. Inorg. Chem. 2002, 171-180.

[65] Z.-K. Chan, T.-R. Chen, J.-D. Chen, J.-C. Wang, C. W. Liu, Dalton Trans. 2007, 3450-3458.

[66] X.-F. Wang, Y. Lv, T.-A. Okamura, H. Kawaguchi, G. Wu, W.-Y. Sun, N. Ueyama, Cryst. Growth Des. 2007, 7, 1125-1133.

[67] N. A. Bell, L. A. March, I. W. Nowell, Inorg. Chim. Acta 1989, $162,57-63$.

[68] R. D. Rogers, A. H. Bond, J. L. Wolff, J. Coord. Chem. 1993, 29, 187-207.

[69] D. A. Pears, J. F. Stoddart, J. Crosby, B. L. Allwood, D. J. Williams, Acta Crystallogr., Sect. C 1986, 42, 51-53.

[70] G. R. Willey, D. R. Aris, W. Errington, Main Group Met. Chem. 2000, 23, 281-284.

[71] H. Zhao, R. Clerac, J. S. Sun, X. Ouyang, J. M. Clemente-Juan, C. J. Gomez-Garcia, E. Coronado, K. R. Dunbar, J. Solid State Chem. 2001, 159, 281-292.

[72] S. Salehzadeh, R. Golbedaghi, I. S. Tidmarsh, L. Sorace, H. Adams, M. D. Ward, Polyhedron 2009, 28, 162-166.

[73] J. C. Jansen, H. Van Koningsveld, J. A. C. Van Ooijen, J. Reedijk, Inorg. Chem. 1980, 19, 170-174.

[74] K. K. Nanda, R. Das, L. K. Thompson, K. Venkatsubramanian, P. Paul, K. Nag, Inorg. Chem. 1994, 33, 1188-1193.

[75] A. P. Ginsberg, R. L. Martin, R. W. Brookes, R. C. Sherwood, Inorg. Chem. 1972, 11, 2884-2889.

[76] A. J. Kinneging, W. J. Vermin, S. Gorter, Acta Crystallogr., Sect. B 1982, 38, 1824-1826.

[77] C. C. Hines, W. M. Reichert, S. T. Griffin, A. H. Bond, P. E. Snowwhite, R. D. Rogers, J. Mol. Struct. 2006, 796, 76-85. 